Illinois State University

ISU ReD: Research and eData

Theses and Dissertations

2-15-2018

\title{
The Relationship Between Perceptions Of Vocal Quality And Function With Self-Esteem In Older Adults
}

Victoria Berto

Illinois State University, vcberto@ilstu.edu

Follow this and additional works at: https://ir.library.illinoisstate.edu/etd

Part of the Speech and Hearing Science Commons, and the Speech Pathology and Audiology Commons

\section{Recommended Citation}

Berto, Victoria, "The Relationship Between Perceptions Of Vocal Quality And Function With Self-Esteem In Older Adults" (2018). Theses and Dissertations. 843.

https://ir.library.illinoisstate.edu/etd/843

This Thesis is brought to you for free and open access by ISU ReD: Research and eData. It has been accepted for inclusion in Theses and Dissertations by an authorized administrator of ISU ReD: Research and eData. For more information, please contact ISUReD@ilstu.edu. 


\title{
THE RELATIONSHIP BETWEEN PERCEPTIONS OF VOCAL QUALITY AND FUNCTION WITH SELF-ESTEEM IN OLDER ADULTS
}

\author{
Victoria Berto
}

65 Pages

Alterations to the voice that occur in older adulthood include changes in vocal fold mass, inadequate approximation of the vocal folds, tremor, and air loss (Lundy, Silva, Casiano, Lu, \& Xue, 1998). Many of the vocal changes that occur in older adults, those aged 65 and older (Colby \& Ortman, 2015), may affect their social and emotional well-being. While some persons are not affected by life span vocal changes, others suffer from co-occurring depression, anxiety, and social withdrawal (Epstein, Hirani, Stygall, \& Newman, 2009; Mirza, Ruiz, Baum, \& Staab, 2003; Monini, Filippi, Baldini, \& Barbara, 2015). There have been numerous studies examining the relationship between vocal and emotional changes; yet no studies, to date, have analyzed the relationship between older adults' perception of vocal change and self-esteem. Therefore, this research explored the association between perceptions of age-related voice problems and selfesteem in older adults. This research also examined gender differences regarding self-esteem levels and vocal concerns, and explored participants' cognition levels, awareness of vocal change, and awareness of vocal resources.

A total of 31 participants completed a questionnaire packet including a demographics questionnaire, the Rosenberg Self-Esteem Scale (RSES), Voice Handicap Index (VHI), researcher-created Voice Self-Esteem Scale (VSES), and the Self-Administered Gerocognitive Examination (SAGE). The VHI examined perceived vocal function and handicap while the 
RSES quantified perceived self-esteem level. The VSES measured voice-related self-esteem and the SAGE screened individuals for cognitive impairment. The results indicated that self-esteem, age, and perceived vocal function were not significantly correlated. However, the majority of the participants scored below the criteria for a mild vocal handicap on the VHI, indicating that participants, as a whole, had minimal vocal concerns. Most participants passed the SAGE cognition screener, indicating that their self-report responses on the demographics questionnaire, VHI, and RSES were likely not influenced by compromised cognition. Men scored higher on all scored questionnaires, yet none of the differences were statistically significant. Thus, it appears that males and females had statistically similar experiences regarding vocal change and levels of self-esteem during this phase of life. Participants who had experienced health conditions that had potential to affect the voice were more likely to indicate an awareness of lifespan vocal changes and healthcare resources to address vocal change. Lastly, the VSES exhibited preliminary evidence of validity. Future studies should refine this scale to best capture voice-related selfesteem in older adults.

KEYWORDS: vocal aging; voice changes; presbylarynx; presbyphonia; gender differences; older adults; elderly; cognition, self-esteem 
THE RELATIONSHIP BETWEEN PERCEPTIONS OF VOCAL QUALITY AND FUNCTION WITH SELF-ESTEEM IN OLDER ADULTS

VICTORIA BERTO

A Thesis Submitted in Partial Fulfillment of the Requirements for the Degree of

MASTER OF SCIENCE

Department of Communication Sciences and Disorders

ILLINOIS STATE UNIVERSITY 
Copyright 2018 Victoria Berto 
THE RELATIONSHIP BETWEEN PERCEPTIONS OF VOCAL QUALITY AND FUNCTION WITH SELF-ESTEEM IN OLDER ADULTS

\author{
VICTORIA BERTO
}

COMMITTEE MEMBERS:

Lisa Vinney, Chair

Kimberly Adelman

Ann Beck

Jean Sawyer

Jamie Smith 


\section{ACKNOWLEDGMENTS}

I would like to thank my family, Mom, Dad, Gemma, and Alessandro for the massive amount of support and love they have shown me from day one. Thank you for teaching me to strive for my personal best. To Kelli, thank you for helping me find my passion and career as a speech-language pathologist. To Nicholas, I may not have pushed myself to tackle this task if you hadn't been so encouraging. Thank you for inspiring me in so many ways. To my committee, Dr. Beck, Dr. Smith, Dr. Sawyer, and Mrs. Adelman. I have learned so much from each one of you in both my undergrad and graduate school careers. I have truly appreciated the countless hours you spent collectively guiding me on my journey. A special thank you to Dr. Beck and Dr. Smith for all the time, effort, and knowledge you both provided towards this project. To Dr. Vinney, the chair of this thesis. I cannot thank you nearly enough for your invaluable guidance, support, encouragement, and friendship. You have gone above and beyond to help me pursue my passion. I have truly enjoyed working with and learning from you. Lastly, I have many more friends, including my peers from the Yellow Group, to thank for helping me achieve this goal.

V. B. 


\section{CONTENTS}

Page

ACKNOWLEDGMENTS

$\begin{array}{ll}\text { CONTENTS } & \text { ii }\end{array}$

TABLES

CHAPTER I: INTRODUCTION 1

Purpose of Investigation 3

Clinical Implications $\quad 4$

Research Questions $\quad 4$

CHAPTER II: LITERATURE REVIEW

$\begin{array}{ll}\text { The Aging Voice } & 7\end{array}$

$\begin{array}{ll}\text { Vocal Aging } & 8\end{array}$

$\begin{array}{ll}\text { Vocal Aging and Gender } & 10\end{array}$

Voice Disorders in the Elderly 11

$\begin{array}{ll}\text { Prevalence } & 12\end{array}$

$\begin{array}{ll}\text { Listeners' Views/Comments } & 12\end{array}$

Voice Disorders in Other Populations 13

Recognizing and Seeking Treatment $\quad 14$

Quality of Life 16

$\begin{array}{ll}\text { Depression/Anxiety/Social Withdrawal } & 18\end{array}$

$\begin{array}{ll}\text { Self-Esteem } & 19\end{array}$

$\begin{array}{ll}\text { Healthcare and Treatment } & 20\end{array}$

$\begin{array}{ll}\text { Summary } & 21\end{array}$ 
$\begin{array}{ll}\text { Purpose } & 23\end{array}$

$\begin{array}{ll}\text { Participants } & 23\end{array}$

$\begin{array}{ll}\text { Survey Instruments } & 24\end{array}$

$\begin{array}{ll}\text { Recruitment Procedure } & 26\end{array}$

$\begin{array}{ll}\text { Data Analysis } & 26\end{array}$

$\begin{array}{ll}\text { CHAPTER IV: RESULTS } & 28\end{array}$

$\begin{array}{ll}\text { Participants } & 28\end{array}$

$\begin{array}{ll}\text { Additional Findings } & 30\end{array}$

CHAPTER V: DISCUSSION

Summary of Study 31

Aging, Perceived Voice Symptoms, and Self-Esteem 31

Cognition, Perceived Vocal Quality and Function, and Self-Esteem 32

Older Men’s Versus Older Women's Self-Esteem and Perceived Vocal Quality and Function $\quad 32$

$\begin{array}{ll}\text { Awareness of Voice Changes } & 32\end{array}$

Adults’ Awareness of Resource 33

Additional Findings $\quad 33$

$\begin{array}{ll}\text { Impressions } & 33\end{array}$

$\begin{array}{ll}\text { Limitations } & 34\end{array}$

Conclusion and Further Research 35

$\begin{array}{ll}\text { REFERENCES } & 37\end{array}$

APPENDIX A: DEMOGRAPHIC QUESTIONS

APPENDIX B: ROSENBERG SELF-ESTEEM SCALE (RSES) 57 
APPENDIX C: VOICE HANDICAP INDEX (VHI)

APPENDIX D: VOICE SELF-ESTEEM SCALE (VSES) 


\section{TABLES}

Table

Page

1. Participant Demographics

2. Health Conditions Listed by Participants with Greater Potential to Impact Vocal Function

3. Number of Individuals Who Indicated Specific Types of Surgery with Potential to Result in Vocal Change

4. Vocal Change Described by Participants

5. Vocal Change Noted in Healthy Individuals and those with Health Conditions with a Greater or Lesser Potential to Affect Vocal Change

6. Number of Participants Who Did or Did Not Indicate Vocal Change in Conjunction with Surgical History Coded as Having Greater or Lesser Potential to Affect Voice

7. Number of Participants Who Did or Did Not Indicate Vocal Change in Conjunction with Health History Coded as Having Greater or Lesser Potential to Affect Voice

8. Average Voice Handicap Index (VHI), Rosenberg Self-Esteem Scale (RSES) and Voice Self-Esteem Scale (VSES) 


\section{CHAPTER I: INTRODUCTION}

The elderly, identified as individuals 65 years or older, are rapidly becoming a large portion of the world population. By 2030, an estimated $20 \%$ of the United States population will be considered older adults. This is a large jump from 1994, when this population was estimated to be 33.2 million compared to a projected 70 million in 2030 (Creighton, Poliashenko, Statham, Abramson, \& Michael, 2013). The drastic increase of individuals in this cohort is notable, as this population is more likely to have health-related as well as social concerns due to natural physiological changes related to aging (Monini et al., 2015). Many of these changes may include the alteration of speech function and production. In fact, by 2050, older adults will comprise approximately $39 \%$ of the speech-language impaired population (Fein, 1983).

During older adulthood, speech impairment may result from a change in voice function and production. These changes often result from anatomic disease or alterations, misuse, overuse, or even emotional correlates, all which may ultimately lead to a voice disorder (Boone, McFarlane, Von Berg, \& Zraick, 2014). A voice disorder is defined as, "any time the voice does not work, perform, or sound as it normally should so that it interferes with communication" (Roy, Merrill, \& Gray, 2005, p. 1989). Voice disorders may result in dysphonia or an impaired voice characterized by, "breathiness, roughness, increased strain or effort with phonation, intermittent voice breaks or aphonia, loss of pitch and loudness range, and vocal fatigue" (Stemple, Roy, \& Klaben, 2014, p.76). While the exact prevalence of voice disorders among the elderly is unknown, population-based studies indicate that voice disorders may occur in anywhere from $4.8 \%$ to $29.1 \%$ of adults 65 years of age and older (de Araújo Pernambuco, Espelt, Balata, \& de Lima, 2015; Vaca, Mora, \& Cobeta, 2015). The latter statistics are significant when compared to the estimated 3-9\% of the general population that suffers from 
voice disorders (Ramig \& Verdolini, 1998; Roy, Merrill, Gray, \& Smith, 2005). Because this rapidly increasing population is more likely to have voice disorders than other demographics, further understanding is needed regarding not only why voice changes/disorders occur in this cohort, but how these changes have an impact on these individuals socially and emotionally.

Adults who suffer from dysphonia may suffer from social withdrawal or isolation and depression. These factors are associated with and may potentially result from voice symptoms such as fatigue during voice production or difficulty with vocal projection (Epstein et al., 2009). Anxiety is also commonly associated with voice problems (Mirza, Ruiz, Baum, Staab, 2003(Golub, Chen, Otto, Hapner, \& Johns, 2006). As a result of voice complications, older adults have commented that they have a decreased desire to interact with others, and have expressed helplessness as well as embarrassment in regard to their voice (Etter, Stemple, \& Howell, 2013). Older adults, who perceive their voice as compromised, may be apologetic to listeners, and note that their voice sounds unfamiliar to them. These perceptions may lead them to stop talking completely. Thus, older adults experiencing age-related voice changes may experience reductions in well-being and quality of life potentially leading to depression and social isolation. Likewise, elderly individuals who elect to work have reported lost wages due to work absences as a result of voice problems (Behlau, Hogikyan, \& Gasparini, 2007; Schwartz, Cohen, Dailey, et al., 2009).

Research has documented a significant relationship between declining levels of selfesteem and increases in age (Robins, Trzesniewski, Tracey, Gosling, \& Potter, 2002). Selfesteem is known as the degree to which people believe they are of value and competent in their surroundings (James, 1983). It is also highly dependent on the appraisal of others (Cooley, 1964). For example, it was found that older adults who had higher attachment levels with others 
had higher levels of self-esteem. Additionally, adults who had supportive and healthy relationships with their children had better subjective well-being and less attachment anxiety (Zhang, Chen, Ran, \& Ma, 2016). Little is known about the relationship between self-esteem and vocal changes in the elderly or if there are gender differences regarding vocal changes or selfesteem that further influence these changes, however, collecting information regarding the selfesteem of older adults with voice concerns is important to these individuals' overall health; as self-esteem, along with personality and demographic variables is known to be one of the most important predictors of subjective well-being (Bosson, Swann, \& Pennebaker, 2000; Schimmack \& Diener, 2003).

The resources available to individuals with specific concerns related to their vocal quality and function are typically acquired from professionals such as otolaryngologists, also known as ear-nose-throat physicians (ENT), or a speech-language pathologists (SLP). These professionals work closely together to assist individuals with vocal concerns (Boone et al., 2014). SLPs are professionals who specialize in the functional evaluation and behavioral treatment of voice disorders. Along with treatment, they also provide counseling, education, prevention, and advocacy (American Speech-Language-Hearing Association, 2017). SLPs are often the first healthcare professional individuals seen for concerns over vocal function (Boone et al., 2014). Therefore, SLPs are most likely to see older individuals who have voice concerns. Thus, SLPs should not only be well-informed about voice problems affecting this population, but also how these changes may relate to self-esteem and life satisfaction.

\section{Purpose of Investigation}

While many studies have documented a positive correlation between voice disorders, social withdrawal, and depression, there are currently no investigations examining the 
relationship between perceived voice problems and self-esteem in the elderly. Therefore, the purpose of this study was to fill this knowledge gap and explore the relationship between selfesteem and perceived age-related voice problems. A secondary purpose of this study was to examine older adults' awareness of vocal change, factors potentially linked to perceived vocal change, and awareness of resources to address vocal concerns.

\section{Clinical Implications}

A better understanding of the relationship between perceptions of vocal aging and function with self-esteem may be useful to healthcare providers and inform professionals, such as SLPs and ENTs as to how to best provide support, resources, and clinical voice care to the growing elderly population. Understanding how voice changes have an impact on the elderly will also assist professionals in providing preventative care and emotional support. Likewise, understanding whether older adults are aware of voice changes and how to address vocal concerns may be useful in facilitating outreach and educational efforts for this population.

\section{Research Questions}

The following research questions were established to focus on the overall implications of agerelated voice changes and self-esteem in the elderly.

\section{Is there a meaningful relationship between aging, perceived voice symptoms, and}

\section{self-esteem?}

a) Rationale: Aging has an impact on the musculature of the larynx, which affects the functioning of the voice. A voice that is abnormal as a result of normal aging processes is characterized as presbyphonic (Kendal, 2007). Many individuals feel insecure and negative about the aging process; yet it is unknown if the functional consequences of the aging larynx are associated with how these individuals view 
themselves. Therefore, the relationships between perceived voice difficulties and the self-esteem in the elderly is warranted.

b) Hypothesis: Greater levels of voice handicap will be associated with lower levels of self-esteem in older individuals.

2. Does cognition act as a moderator between perceived vocal quality and function and self-esteem?

a) Rationale: Cognitive changes related to aging may affect older individuals' awareness of physiological changes (Diehl, Wahl, Barrett, et al., 2014). Therefore, these individuals may not seek the help they need if they are unaware of issues regarding their voice production.

b) Hypothesis: Individuals who have lower scores on a cognitive screener, are less likely to be aware of vocal changes due to their decreased insight and awareness of themselves and their surroundings.

\section{Are there differences between older men's versus older women's self-esteem and} perceived voice quality and function?

a) Rationale: Men and women experience different physiological changes as they age, resulting in different vocal quality changes for these two populations (Zraick, Gregg, \& Whitehouse, 2006). Women are also more likely to report struggling with hoarseness, decreased volume, raspiness, and breathiness, among other symptoms (Gregory, Chandran, Lurie, \& Sataloff, 2012). Furthermore, self-esteem also differs depending on gender. Specifically, self-esteem levels are lower in women until 80 years of age. From 80 years onward, women's self-esteem levels begin to surpass their male counterparts (Robins, Trzesniewski, Tracy, Gosling, \& Potter, 2002). 
Hypothesis: Yes, there are gender differences in self-esteem and perceived voice handicap resulting from differences in vocal quality and self-esteem levels between men and women. It is predicted that women will score higher on the voice handicap index (a measure of perceived voice problems) and lower on self-esteem scales.

\section{Are older adults aware of voice changes related to aging?}

a) Rationale: Adults should experience age-related vocal alterations and their awareness of these changes is likely to be linked to whether or not they seek help for any voice-related changes.

b) Hypothesis: It is predicted that most older adults are aware of vocal changes.

\section{Are older adults aware of the resources available to them to address voice-related}

\section{concerns?}

a) Rationale: Older adults have indicated that they understood the value of having a healthy voice, but knew little about what they could do or how they could improve their voices (Etter et al., 2013). Further, many older adults do not seek professional help for voice concerns, and may discount vocal concerns as unavoidable or untreatable (Monini et al., 2015).

b) Hypothesis: It is predicted that many older adults, as a whole, are not aware of the resources available to them when vocal concerns or disorders arise. 


\section{CHAPTER II: LITERATURE REVIEW}

\section{The Aging Voice}

In the recent past, little systematic and objective research on physiologic voice changes in older adults existed (Weismer \& Liss, 1991). Researchers Xue and Hao (2003) claimed that this lack of data may have stemmed from the scarcity of appropriate tools and research methods to analyze the way in which the voice ages. Thus, describing age-related voice changes was often exclusively based on researchers' subjective perceptions of voice quality. However, in the early 2000s the reliance on technology greatly assisted in further developing researchers' understanding of vocal anatomy and how it ages (Xue \& Hao, 2003). Currently, vocal aging changes are documented via observation and self-evaluation, in addition to assessment of oralperipheral structures, resonance, and respiration, auditory-perceptual assessments, and instrumental assessments (American Speech-Language-Hearing Association, 2017). Such instruments include tools that measure laryngeal functioning, such as a flexible or rigid videolaryngoscopes. Laryngoscopes can be used to view how vocal fold structure and function differ between individuals in older, mid, and younger adulthood (Pontes et al., 2005). Instrumentation is also used to quantify acoustic measures of voice production such as amplitude, frequency, and quality of the voice, while instrumental aerodynamic assessments examine characteristics like glottal airflow or subglottal air pressure (American SpeechLanguage-Hearing Association, 2017). Thus, the use of modern technology, in conjunction with other assessment tools, has led to a deeper understanding of the aging larynx and vocal folds across the last several decades. 


\section{Vocal Aging}

Older adulthood, according to the 2015 U.S. Census Bureau, is classified as beginning at age 65 (Colby \& Ortman, 2015). Natural changes in the larynx commonly compromise vocal functioning in older adults (Pontes, Brasolotto, \& Behlau, 2005; Pontes, Yamasaki, Behlau, 2006; Gregory, Chandran, Lurie, \& Sataloff, 2012). Vocal aging may result from natural physiological or anatomical changes due to muscle loss, much like the rest of the body (Ziegler \& Hapner, 2013). This muscle loss results in vocal fold and laryngeal aging known as presbyphonia (Sinard, 1998). Presbyphonia, or presbylarynx are terms used to describe changes in the voice or larynx that occur due to normal aging (Kendal, 2007),

Vocal changes related to aging, or presbylarynx, may begin even before 65 years of age, however, a longitudinal study over a period of 5 years examined the vocal aging process of 20 men between the ages of 51 and 81 (Verdonck-de Leeuw \& Mahieu, 2004). Questionnaires were completed regarding each participant's vocal ability/perception and social interaction. Vocal tasks were also completed, recorded, and analyzed professionally. During the 5-year time lapse, many of the participants experienced age-related voice changes that resulted in decreased levels of socialization. Data from this study show that even adults as young as 51 years of age may experience a change in their voice production over a 5-year time period.

Some common laryngeal changes that occur in older adulthood include vocal fold atrophy, thinning of the vocal ligaments, ossification of the laryngeal cartilages, and thinning and thickening of the epithelial layer of the vocal folds. In particular, a reduction in the thickness of the lamina propria as well as in the epithelial lining of the vocal folds was found in the larynges of cadaver men and women who lived from 30 to 90 years of age (Ximenes, Tsuji, do Nascimento, \& Sennes, 2003). Researchers found a 1\% reduction in the thickness of the 
epithelium and lamina propria during each year of life for both sexes. These findings conflict with various studies, which found that during older adulthood, the epithelium thickens in women and thins in men (Hirano, Kurita, Sakaguchi, 1989; Ximenes, Tsuji, do Nascimento, \& Sennes, 2003).

Laryngeal age-related changes found by Hirano et al. (1989) include changes to vocal fold mass and inadequate vocal fold approximation and tension as well vocal tremor, and air loss during phonation. Additionally, a membranous spindle-shaped glottic chink, or bowing of the vocal folds, is commonly found in adults with presbylarynx (Pontes, et al., 2005). Bowing results in a space between the vocal folds (Pontes, et al., 2005). Since the vocal folds are typically adducted (completely closed) during phonation, a gap between them will result in air escaping and a breathy voice quality. Additionally, vocal fold bowing and/or atrophy is associated with wheezing symptoms or a high-pitched, continuous sound that may indicate difficulty breathing (Pontes, et al., 2005, Mayo Clinic, 2017). Others may also perceive vocal hoarseness or roughness in older adult voices due to the previously described range of physiological vocal changes, while older speakers themselves may complain of vocal fatigue (Verdonck-de Leeuw \& Mahieu, 2004). Despite these potential reductions in vocal quality and increases in vocal effort, Pontes et al., (2005) indicated that presbylarynx may, in fact, protect older adults from acquiring mucosa alterations of the vocal folds. Leukoplakia (a precancerous vocal fold growth) is a form of mucosa alteration that may occur to a lesser extent in individuals with presbylarynx with vocal fold bowing. Findings indicate that the reduced vocal fold contact, resulting from bowing, may be protective against the formation of leukoplakia; which has more severe consequences than vocal aging alone (Pontes, et al., 2005). 
Changes in the vocal tract, in addition to laryngeal structure and function, may affect vocal output. Specifically, Xue and Hue (2003) found that the entirety of the vocal tract may not age at the same rate, across both men and women, using acoustic reflection (AR) technology. In particular, during older adulthood, oral cavities lengthen and oral volumes increase, while pharyngeal volumes stay consistent. These dimensional changes, alone and relative to one another, may result in vocal quality changes.

Additional factors may also influence vocal aging, such as alteration of the laryngeal structures previously described, changes in lip rounding/articulation, and respiratory functioning. For instance, lip rounding increases the length of the vocal tract, which changes vocal quality (Titze, 1994). Declines in respiratory functioning may have an impact on vocal projection and endurance as well as listeners' overall ability to hear an older adult speaker (Sinard, 1998). Poor respiratory function may also decrease maximum phonation time and overall vital capacity while increasing expiratory stress. These factors together may affect the rhythm and intensity of speech (Mezzedimi, Di Francesco, Livi, Spinosi, \& De Felice, 2017).

From the gathered research, it is apparent that vocal aging may interfere with breath support for phonation, vocal projection, vocal quality, and even speech characteristics like articulation. The consequences of such changes may include reductions in communication that compromise vocational and social pursuits. Despite these potentially negative consequences, age-related anatomical changes, likely to lessen vocal fold contact, may prevent older adults from acquiring more severe voice disorders or growths as their larynx ages.

\section{Vocal Aging and Gender}

To best understand how the larynx and vocal tract age over time, one must also be cognizant of the differences between men and women. Hormones, such as estrogen, account for 
a major difference in how men and women experience changes related to aging (Ximenes, Tsuji, do Nascimento, \& Sennes, 2003). For example, thinning of older men's and the thickening of older women's vocal folds is thought to lead to increases in habitual pitch in men and decreases in pitch for women (Zriack et al., 2006). Edema, or swelling of the vocal folds due to water retention, results in thicker vocal folds and a decreased pitch in women (Close \& Woodson, 1989). In fact, the most obvious change in women's fundamental frequency occurs after the completion of menopause, when vocal fold edema is most common (Linville, 1987). Women are also more likely to experience vocal concerns, decreased volume, hoarseness, raspiness, and breathiness, compared to men (Gregory et al., 2012). On the other hand, changes in laryngeal tissue as well as ossification of cartilages are known to occur earlier in life in men than women (Kahane, 1987). Overall, vocal fold atrophy seems to be more prevalent in older men $(67 \%)$ than in women (26\%; Honjo \& Isshiki, 1980). While gender differences account for variability in vocal aging, both sexes may attempt to alter their voices to compensate for perceived changes. For example, an older male may try to hide his unstable and high-pitched voice, while an older female may try to conceal her lower-pitched, raspy voice (Hollien, 1987).

\section{Voice Disorders in the Elderly}

Older adults are more prone to changes in their vocal functioning due to natural physiological changes of the larynx. They are, however, also prone to other pathological conditions which may have an impact on vocal ability. Central neurological disorders, such as Parkinson's disease, stroke, etc. are more likely to strike older adults and affect their larynges, while vocal fold inflammation due to pharmacological side effects is also common. Further, voice disorders such as Reinke's edema, muscle tension dysphonia, epithelial dysplasia (i.e., laryngeal cancer), or vocal fold paralysis are more commonly diagnosed in older versus younger 
adults (Vaca, et al., 2015; Gregory et al., 2012; Kendal, 2007). It is important to note, however, that in past studies, researchers have attempted to isolate variables that distinguish vocal aging from pathology, but were unsuccessful (Decoster \& Debruyne, 2000). Thus, differentiating between typical laryngeal physiological and structural age-related changes from voice disorders that are more prevalent in older adults, would assist in providing more appropriate prevention methods as well as rehabilitative techniques (Pontes, et al., 2005).

\section{Prevalence}

The prevalence of vocal concerns/disorders in older adults is unknown, but thought to be more common than in other age groups. Population-based studies indicate $4.8 \%$ to $29.1 \%$ of older adults have concerns about their voice (de Araújo Pernambuco, Espelt, Balata, \& de Lima, 2015). Despite the prevalence data provided, sufficient data have not been gathered regarding older adults' true vocal concerns or perceptions of vocal change due to presbylarynx (Plank, Schneider, Eysholdt, Schutzenberger, Rosanowski, 2011) and no survey, to date, exists that accurately measures the prevalence of "geriatric dysphonia" in the U.S. (Golub et al., 2006). Yet, individuals who are diagnosed with a voice disorder are more likely to acquire another voice disorder in their lifetime (Roy, et al., 2007; Roy, et al., 2005). This statistic implies that if an adult has a voice disorder at a young age, he or she may be at a higher risk for acquiring a voice disorder later in life. Additionally, if adults who acquire a voice disorder in older adulthood are more likely to have ongoing issues with their voice due to a combination of consequences from normal aging and the disorder itself.

\section{Listeners' Views/Comments}

Age-related voice changes are typically a normal part of aging; however, while some older individuals are satisfied with their voices, many elderly individuals are cognizant of vocal 
changes and may feel the need to apologize for them to listeners (Etter et al., 2013). Furthermore, most of these vocal changes may be easily identified by listeners, enabling them to estimate the approximate age of the speaker (Gregory et al., 2012). In fact, research has indicated that many older adults believe that the sound of their voice causes listeners to inquire about their overall health or if they are seeking help for compromised voice quality (Etter et al., 2013). Thus, "What's wrong with your voice?" may be a common question that older individuals encounter from listeners, whether it be from family members or strangers; especially when "voice tremor, laryngeal tension, air loss, imprecise consonants, and slow rate of articulation" are noted (Ryan $\&$ Burk, 1974, p. 181). Such a question may come up when a speaker and listener are communicating through the telephone. For example, one older adult male participant study by Etter et al. (2013), noted that he was frequently mistaken for a woman when communicating by phone; this was likely due to a higher-pitched voice resulting from vocal fold thinning.

The distinct quality of older adults' voices may have become more apparent in the past couple of decades with the increase in adults over age 65 (Creighton, Poliashenko, Statham, Abramson, \& 3rd, 2013). The consequences of vocal aging, however, have been noted across the centuries by writers, vocalists, etc. For instance, Shakespeare characterized the older adult male voice as turning "toward childish treble pipes, and whistles in his sound." (Shakespeare, As You Like It, Act 2, Scene 7).

\section{Voice Disorders in Other Populations}

An understanding of voice disorders and age-related changes in older adults and their perceived affect may be improved by also analyzing vocal changes and pathologies in other age groups. The prevalence of voice disorders among children ranges from $6 \%$ to $23.4 \%$, and are even greater from ages five to 10 years (Melo, Mattioli, Brasil, Behlau, Pitaluga, \& Melo, 2001). 
Studies have shown that children with voice disorders are viewed negatively by peers and adults (Ruscello, Lass, \& Podbesek, 1988; Lass, Ruscello, Stout, \& Hoffmann, 1991; Lass, Ruscello, Bradshaw, \& Blankenship, 1991). Further, when a child is diagnosed with vocal fold nodules, resulting in hoarseness, his/her ability to communicate effectively in everyday life may negatively affect school success, participation in daily activities, and overall mood (Zur, Cotton,

Kelchner, Baker, Weinrich, \& Lee, 2007). These negative reactions, whether to children or older adults with voice problems, demonstrate the necessity for effective assessment and treatment for voice problems (Etter et al., 2013).

A study using parents' ratings of their child's voice-related quality of life (V-RQOL) and pediatric dysphonia (i.e., compromised voice quality), found no relationship between them (Souza, Nunes, Friche, \& Gama, 2017). The researchers speculated that parents may have been unable to detect dysphonia in their child; particularly if their child's voice had been similarly compromised since infancy (Wilson, 1979; Paixao, Siqueira, Coelho, Brasolotto, \& Silverio, 2015). From these findings, one may assume that voice disorders among young children may, in some cases, go relatively unnoticed due to lack of awareness or knowledge. Thus, a child with a voice disorder who goes unnoticed and untreated may suffer more severely compromised voice quality in many stages of life, including older adulthood.

\section{Recognizing and Seeking Treatment}

Even though the prevalence of voice disorders in older adults is greater than in other populations, many individuals believe that there is no help available to address voice concerns and that dysphonia is a normal part of aging (Tuley \& Cohen, 2009; Roy, Merrill, Gray, \& Smith, 2005; Cohen, 2010; Golub, Chen, \& Otto, et al, 2006). These beliefs may stem from an external locus of control or the belief that one is not directly in control of his/her own life 
(Levenson, 1973). External locus of control is negatively correlated with coping among older adults. Specifically, participants in one study who believed they were not in control of their own lives had a harder time coping with their voice disorder, but those who believed they were in control of their lives used coping strategies more effectively (Oliveira, Hirani, Epstein, Yazigi, \& Behlau, 2012). This finding may indicate that the older adults who do seek help for their voice believe that they are able to remediate them, while those who have an external locus of control choose not to address these concerns.

Other explanations as to why older adults may not seek help for voice concerns include difficulties traveling to a voice provider, an overall lack of concern about compromised vocal function or quality, or treatment that is too costly or time-consuming (Tuley \& Cohen, 2009). Yet, despite these findings, other research has documented older adults' refusal to talk on the phone or speak in public due to the instability of their voices (Etter et al., 2013). Such findings indicate that voice problems may lead to potential negative impacts on quality of life (QOL).

An additional study including 400 older adults, aged 65 years or older, found that $65 \%$ of participants felt their vocal quality was altered and that $31.5 \%$ of the studied population had some form of vocal pathology resulting in compromised voice quality (i.e., increased asthenia, breathiness, roughness, and strain). Specifically, participant's responses on the Voice Handicap Index (VHI), indicated that they perceived their voice as compromised (Monini et al., 2015). Furthermore, many of the individuals with vocal pathology underestimated their vocal issues. When the participants were asked whether they had sought treatment for voice concerns, many said they had not, but thought that they should have (Monini et al., 2015).

The data from this studied population showed that the presence of their vocal pathology was poorly correlated to their subjective perceptions of their voice (Monini et al., 2015). Thus, 
while older adults may indeed have diagnosable vocal pathologies, many of them do not perceive these pathologies as problematic. The implications of this research are that older adults are often unaware of vocal pathologies which may then prevent them from seeking help and receiving appropriate care. This lack of appropriate care is likely to affect the psychosocial, physical, and functional aspects of the individual's life (Monini et al., 2015). One may assume that a lack of awareness regarding vocal changes and concerns may also be a result of declines in cognition (Diehl, Wahl, Barrett, et al., 2014), which may further influence help-seeking.

Even though many older adults are unaware of their voice changes and therefore neglect searching for appropriate care, older adults have stated their voices are important to them in their everyday lives (Etter et al., 2013). For example, when 28 older adults were interviewed about their voices, approximately $79 \%$ of the adults who were receiving voice services from SLPs indicated that they valued their voices and saw them as vital to who they were as individuals. Participants also stated their voices were especially important when connecting with others. A majority of the older adults indicated that they were "hindered" in some way due to their voice and were either hesitant to talk to others, felt alone, or needed help from others to communicate. Similarly, almost $93 \%$ of the participants noted that they did not like how their voice sounded despite exerting considerable energy to talk. Finally, 19 of the 28 participants felt their voices influenced their emotions, in that they were irritated or frustrated by their voice (Etter et al., 2013). From the data collected by Etter et. al., it is apparent that vocal changes related to aging may significantly compromise QOL in functional, physical, and emotional domains.

\section{Quality of Life}

QOL is a multi-dimensional concept that includes positive and negative evaluations of life encompassing one's health, job, culture, among other areas (Center for Disease Control and 
Prevention, 2016). Etter et al. (2013) studied QOL in older adults with voice problems by asking participants to list specific ways in which their vocal changes affected their everyday habits and functioning. Despite indicating these specifics, many noted that theirs global QOL was not affected by their vocal changes. This finding shows that professionals, such as SLPs, may not attain a clear picture of an individual's voice disorder or the limitations resulting from it without comprehensive evaluation. These results also indicate that older adults might not fully recognize or might even discount how voice changes affected their daily lives (Etter et al., 2013).

The ability to cope with voice disorders or changes may be influenced by depression and anxiety (Epstein, Hirani, Stygall, \& Newman, 2009; Mirza, Ruiz, Baum, Staab, 2003). It is important to systematically examine how these particular diagnoses affect QOL in older adults. Researchers Turley and Cohen (2008) studied the relationship between QOL and the prevalence of dysphonia and dysphagia in 248 old adults over the age of 65 , with a mean age of 82 years. Of the participants, $19.8 \%$ had dysphonia, $13.7 \%$ had dysphagia, and $6 \%$ had both. Measurements to attain QOL scores were derived from the Voice-Related Quality of Life (V-RQOL), a 10-item self-administered questionnaire that measures how the voice affects the perceptions an individual has regarding their QOL and overall life satisfaction. Those who were diagnosed with dysphonia had significantly lower V-RQOL than those without dysphonia, and those with both dysphonia and dysphagia had even lower V-RQOL scores (Turley \& Cohen, 2008). Furthermore, those with either dysphonia or dysphagia had higher levels of self-reported depression than those without, and those with both conditions had even greater levels of depression (Turley \& Cohen, 2008). Thus, it is apparent that age-related dysphonia may be related to increased levels of depression and reduced QOL. 


\section{Depression/Anxiety/Social Withdrawal}

Depression and anxiety in individuals with voice disorders is an area of interest for researchers because of findings related to reduced QOL and decreased socialization in relationship to voice problems (Dietrich, Verdolini-Abbot, Gartner-Schmidt, \& Rosen, 2008). For example, Dietrich et al. (2008) found that individuals with voice disorders exhibited levels of anxiety greater (but not significantly so), than those without voice disorders. They also found that certain voice disorders were more likely to occur with increased stress, anxiety, and depression. This same study found that women were more likely to experience anxiety because of voice disorders than men, and experience anxiety more commonly than depression (Dietrich et al., 2008).

Voice disorders or complications may also affect an individual's professional life resulting in occupational change, missed days of work, and effective job performance (Roy, Merrill, Gray, \& Smith, 2005). Similarly, while many older adults may be retired or no longer working regularly, voice problems in this population may increase social isolation or withdrawal because of the challenges associated with being heard on the telephone or over other speakers in a room. Social events for individuals with voice problems may then become a source of increased anxiety which may, in turn, further increase social isolation (Roy, Stemple, Merrill, Thomas, 2007).

Results of various studies have indicated that older adults may be at a higher risk for depression, anxiety, and social isolation related to voice complications due to aging as or vocal pathology (Dietrich, Verdolini-Abbot, Gartner-Schmidt, \& Rosen, 2008; Roy, Merrill, Gray, \& Smith, 2005; Roy, Stemple, Merrill, Thomas, 2007). These factors may play a role in decreasing QOL, affecting an overall ability to live a productive and healthy lifestyle. Altogether, such 
factors may influence overall perceived self-worth known as one's self-esteem (Mullen, Gothe, \& McAuley, 2013).

\section{Self-Esteem}

Self-esteem is known as the degree to which people believe they are of value and competent in their surroundings (James, 1983). Although self-esteem may fluctuate throughout an individual's lifetime, those with poorer self-esteem are likely to maintain relatively low selfesteem levels throughout their lives (Orth, Maes, \& Schmitt, 2015). Self-esteem may fluctuate depending on one's age and developmental stage. Research has documented that self-esteem begins to increase during adolescence and continues to increase and eventually peak at around 60 years of age. However, studies have indicated inconsistent changes (declines or increases) in self-esteem levels in older adulthood (Orth, Trzesniewski, \& Robins, 2010(Robins et al., 2002)).

Trends in self-esteem in the elderly require further study due to inconsistent theories and findings in the current literature (Robins et al., 2002). For example, some researchers believe that self-esteem does not decrease in older adulthood because this construct may be less affected by life events and stages, such as aging (Crocker \& Wolfe, 2001). Self-esteem levels may also differ by gender, as research has found that females typically have lower levels of self-esteem compared to males (Steiger, Allemand, Robins, \& Fend, 2014). However, some studies have found no differences in gender when comparing levels of self-esteem (Harris, Donnellan, \& Trzesniewski, 2018). It is not until about 70 years of age that women have a comparable level of self-esteem to their male counterparts. Interestingly, when both sexes reach the $80^{\text {th }}$ year of life, women are statistically shown to surpass men in levels of self-esteem (Robins et al., 2002). Women typically use more coping strategies when dealing with health-related complications such as voice-related concerns, and are also more verbal in expressing those concerns throughout 
their lives (Tamres, Janicki, \& Helgeson, 2002). These characteristics may be especially integral to better self-esteem in women relative to men over age 80 . For example, coping with health concerns and increased communication about life difficulties may lead to increased emotional support from friends and family, and potentially referrals to specialists such as ENTs or SLPs.

\section{Healthcare and Treatment}

ENTs and SLPs specialize in providing diagnoses and treatment for individuals with vocal concerns (Boone et al., 2014). Those older individuals, without a vocal pathology, who seek help for voice concerns will typically be diagnosed with presbyphonia so that management approaches may be targeted towards compensating for natural age-related voice changes. In fact, older individuals found to have presbyphonia as a diagnosis of exclusion, or with no other vocal pathologies, are still generally thought of as having a voice disorder simply because voice disorders may be defined as the voice interfering with communication or sounding different than usual (Roy, Merrill, \& Gray, 2005, p.1989). While natural aging of the voice may not be a pathology itself, it may affect the individual's QOL, as their aging voice may result in communicative barriers.

While ENTs and SLPs are the primary providers for adults with presbyphonia, they may also collaborate with other professionals such as neurologists, allergists, endocrinologists, gastroenterologists, pulmonologist, and occupational medicine physicians. SLPs are trained and capable of providing counseling services to patients in need; however, if professionals feel the clients require additional counseling services outside of their scope of practice, they may refer the client to a psychologist. If there is a relationship between low self-esteem and perceived voice changes, however, there is a great need to address both components when providing specialized treatment. A better understanding and exploration of how professionals target 
treatment to address age-related vocal changes, while also addressing psychological components, is necessary to appropriately serve older adults.

Treatment for voice care comes in various forms. While there are surgical options available, voice therapy is non-invasive, less costly, and may facilitate vocal behavior changes that effectively remediate or compensate for age-related voice changes in a healthy way. Therapy approaches may be direct or indirect in nature or a combination of each (American SpeechLanguage-Hearing Association, 2017). Direct therapy focuses on individuals changing their vocal behavior and technique to increase the safety and efficiency of vocal output (Colton \& Casper, 1996; Stemple, 2000) while indirect therapy is focused on modifying emotions or behaviors (e.g., drinking more water, smoking cessation) that may affect vocal health and output via education and counseling (Roy, et al., 2001; Thomas \& Stemple, 2007). Voice therapy may facilitate decreased vocal effort during voice production, and decreases in perceived dysphonia symptoms while also leading to increased ratings of overall QOL, voice-related QOL, and selfperceptions of vocal quality in individuals with presbylarynx (Sauder, Roy, Tanner, Houtz, \& Smith, 2010; Ziegler \& Hapner, 2013; Gregory et al., 2012). Thus, voice therapy might not only address underlying voice symptoms, but might improve other symptoms that are related to psychological well-being.

\section{Summary}

The increasing population of older adults requires a strong understanding of the psychosocial and healthcare needs of this population (Creighton et al., 2013). Specifically, identifying how psychosocial factors such as self-esteem and QOL might be related to perceived age-related changes among this population might better prepare healthcare providers to 
effectively educate, communicate with, and treat older, and provide more holistic, targeted, and effective voice services for older adults.

In particular, a full investigation as to how self-esteem is related to perceived voice changes in older adults is warranted. Many older adults may not be aware of vocal changes, yet might still use coping techniques to assist themselves in their everyday lives. This suggests that these older adults might subconsciously accommodate for vocal changes, and yet not seek professional services to treat dysphonia (e.g., ENT or SLP). Thus, a further understanding of this population's knowledge of available services to address voice concerns and how aware they are of voice changes in general will inform future efforts to assess and treat voice problems in older adults. 


\section{CHAPTER III: RESEARCH DESIGN}

\section{Purpose}

The purpose of this research was to investigate the relationship between aging, perceived vocal quality and function, and self-esteem in older adults. Older adults' knowledge of vocal changes and services to address vocal concerns also requires further exploration. Thus, this study addressed the following research questions:

1. Is there a meaningful relationship between aging, perceived voice symptoms, and self-esteem?

2. Does cognition act as a moderator between perceived vocal quality and function and self-esteem?

3. Are there differences between older men's versus older women's self-esteem and perceived vocal quality and function?

4. Are older adults aware of voice changes related to aging?

5. Are older adults aware of the resources available to them to address voice-related concerns?

\section{Participants}

According to the 2015 U.S. Census Bureau, older adults are classified as individuals ages 65 years or older (Colby \& Ortman, 2015). Thus, male and female participants who are 65 years or older were targeted for this study. Because normed self-report measures exist to quantify perceived vocal handicap and self-esteem, such measures were used to investigate whether respondents' perceptions of their voices hold a significant relationship with self-esteem levels, in addition to cognition, awareness of help, and gender differences. 
Participants were recruited from five senior community centers: The Activity and Recreation Center (ARC) in Normal, IL; the Illinois State University (ISU) Alumni Center in Normal, IL; the Illinois State University Speech and Hearing Clinic in Normal, IL; Westminster Village in Bloomington, IL; and the East Wing Glenview Senior Center in Glenview, IL. Inclusion criteria for participants required they be 65 years of age and able to complete written questionnaires without assistance from others.

\section{Survey Instruments}

Participants were provided with a consent form and five questionnaires. Each packet contained demographic questions, the Rosenberg Scale of Self-Esteem (RSES), the Voice Handicap Index (VHI), a scale created by the researcher, named the Voice Self-Esteem Scale (VSES), and the Self-Administered Gerocognitive Exam (SAGE). More information on each of these measures is provided in subsequent paragraphs. The questionnaires were provided in a randomized order to ensure order effects did not influence questionnaire results.

The demographics questionnaire (APPENDIX A) asked participants to list surgeries, current and past medical conditions, answer a number of questions about vocal use, and respond to the following:

- Has the sound of your voice changed over your lifetime? If so, how and when?

- Are you aware of any resources or supports that you could contact if you had trouble with your voice? Please list.

The RSES (see APPENDIX B) is a normed test that measures global self-esteem levels in individuals. This 10-item questionnaire also uses a 4-point Likert scale with 1 representing "strong agreement" and 4 indicating "strong disagreement" with each provided statement regarding aspects of self-esteem (e.g., "I feel I do not have much to be proud of"). Each item 
may target either negative or positive views of the individual, with negative items being reverse scored. Higher scores correlate with higher levels of self-esteem (Rosenberg, 1965). The RSES was utilized in this study to document each participant's level of self-reported self-esteem.

The VHI (see APPENDIX C) is a normed self-report tool designed to measure perceived vocal handicap via functional, physical, and emotional subscales that total 10 questions each. The inventory is comprised of 30 questions that participants rate on a four-point scale with 0 indicating "never" and 4 indicating "always" for statements such as "my voice makes it difficult for people to hear me." A higher score indicates more perceived vocal handicap with thresholds for each subscale and overall that are representative of mild, moderate, or severe self-perceived vocal difficulties (Jacobson, et al., 1997). The VHI was used in this study to identify individuals with various levels of self-perceived voice handicap.

The VSES (see APPENDIX D) is a questionnaire created for the present study to assess voice-related self-esteem. The format of the RSES was used as a guide for the design of the VSES, while the VHI questions were also referenced to design statements that connect selfesteem and perceived voice handicap with one another. This 12-item scale follows the 4-point Likert scale, with 1 indicating "strong agreement," and a 4 indicating "strong disagreement" with each provided statement (e.g. "I would socialize with others more if I was more accepting of my speaking voice"). A lower score on this measure indicates a greater degree of voice-related selfesteem. Positively worded questions are reverse scored.

The SAGE (see APPENDIX E), is a normed screening test that shows test-retest and inter-rater reliability for detecting a potential diagnosis of cognitive impairment in the elderly (Scharre, 2016). A score at or above 17 out of a possible 22 is considered indicative of typical cognitive status. This screener was administered to document the cognitive status of all 
participants. The researcher planned to compare questionnaire data (e.g., perceived vocal handicap and self-esteem and awareness of vocal change and resources to treat voice problems) in those with cognition outside normal limits to those with cognition within normal limits.

\section{Recruitment Procedure}

Each senior facility's site coordinator agreed to allow recruitment of site members/attendees for the study. The researcher posted fliers and made in-person announcements to specific classes at each location. Fliers/announcements briefly explained the study and inclusion criteria for participation. During each in-person announcement, individuals were invited to pick up a survey from the researcher or do so at the front desk of the facility from which they were recruited. Participants were then asked to complete an initial consent form and each survey measure anonymously, based on written directions provided. Once completed, individuals were encouraged to drop off surveys in a designated and sealed mailbox within their facility. This project was approved by Illinois State University's Institutional Review Board.

\section{Data Analysis}

After data collection, results were analyzed statistically using Statistical Package for the Social Sciences (SPSS) software. The relationship between scores on the VHI and RSES was explored via Pearson correlation, and secondary analysis of vocal use ratings in relationship with the VHI and RSES was assessed through Fisher's Exact Test (research question 1). VSES results were also correlated with both the VHI and RSES to determine whether the VSES adequately captured the constructs of self-esteem and voice handicap. The researcher planned to place participants into two groups (individuals with cognition within normal limits and individuals with potentially impaired cognitive status) in order to analyze if there was a significant difference between groups in regard to age, the VHI, RSES, and VSES (research question 2). 
Independent T-tests were also used to determine whether male and female participants' perceived self-esteem and voice handicap significantly differed based on RSES, VHI, and VSES results (research question 3). Descriptive statistics, reported via the demographics questionnaire, were used to document the number of participants who indicated vocal changes in later life and an awareness of available resources or supports for voice difficulties based on the questions noted above (research questions $4 \& 5$ ). Participants' health conditions and surgeries were also coded into two categories: (1) conditions with an increased potential to impact the voice (e.g., due to side effects such as nerve damage, hormonal changes, laryngeal irritation, etc.); and (2) conditions with lesser potential to impact the voice (e.g., hip replacement, skin cancer, etc.). A $2 \times 3$ chi-square test, was used to examine the relationship between coded health conditions and awareness of vocal change. Alpha level was set at $<.05$ for all statistical analyses. 


\section{CHAPTER IV: RESULTS}

Data were analyzed from all questionnaires returned by participants. Not all participants completed the full questionnaire packet or individual test measures (Demographics, SAGE, VHI, VSES, and RSES). Incomplete test measures were excluded from data analysis.

\section{Participants}

Demographic data are provided in Table 1. Thirty-one participants completed the questionnaire packet. Average participant age was 74.1 years (SD: 4.99), with a minimum age of 66 and a maximum age of $85(n=30)$. Thirty participants completed the SAGE (mean: 20.5, SD: 2.5) and two fell below 17 (indicating possible cognitive impairment), receiving a score of 15 and 13 out of the 22 possible points given. The results of the SAGE indicate that the sampled population of individuals was within or just below the norm for typical cognitive status, compared to typically aging adults.

Health conditions and surgeries with a greater or lesser potential to affect vocal function are reported in Table 2. Surgeries listed by participants with the potential to affect vocal function (Table 3) were commonly noted among participants (e.g., more than a quarter of participants indicated undergoing tonsillectomies and hysterectomies). Thyroidectomy and coronary arterial bypass graft were the second most common surgeries, followed by hypothyroidism, malignant melanoma of the neck, goiter around the trachea, deviated septum, sinus conditions, and tongue cancer. Vocal changes described by participants are listed in Table 4. Results related to primary research questions are provided below.

\section{Is there a meaningful relationship between aging, perceived voice symptoms, and} self-esteem?

No significant correlation was found between age and RSES $\left(r_{x y}=.036, \mathrm{p}=.855\right)$, age and 
VHI $\left(r_{x y}=-.153, \mathrm{p}=.428\right)$, or age and the created VSES measure $\left(r_{x y}=-.151, \mathrm{p}=.453\right)$. VHI and RSES were also not significantly correlated $\left(r_{x y}=-.286, \mathrm{p}=.070\right)$. Secondary analysis of vocal use ratings in relationship with VHI and RSES ratings were also explored. Visual inspection of the data revealed a potential trend toward higher VHI/RSES scores among the group with minimal voice use. Fisher's Exact Test was used to assess this trend. The results were not statistically significant for VHI $(p=.186$, Fisher's Exact Test) or the RSES $(p=.281$, Fisher's Exact Test).

2. Does cognition act as a moderator between perceived vocal quality and function and self-esteem?

Because only two participants did not pass the cognitive screener, two groups of individuals (those who passed and who did not pass the screen) could not easily be used to analyze differences in RSES, VSES, and VHI data. As a result, the data did not lend itself to address this research question.

\section{Are there differences between older men's versus older women's self-esteem and perceived vocal quality and function?}

Table 8 reports the descriptive statistics used to assess this question. Although men had higher average scores on the VHI, RSES, and VSES scales, these differences were not statistically meaningful. Independent T-tests were used to analyze the difference between men and women on following scales: RSES $(\mathrm{t}(26)=.909, \mathrm{p}=.372)$, VSES $(\mathrm{t}(25)=.518, \mathrm{p}=.609)$, and the VHI $(\mathrm{t}(28)=.892, \mathrm{p}=.380)$. No significant differences were found.

\section{Are older adults aware of voice changes related to aging?}

Of the 31 participants, 12 of them, or $38 \%$ noted vocal changes. Awareness of voice change was calculated based on the responses to questions in the demographics section of the 
questionnaire packet (e.g., "has the sound of your voice changed over your lifetime? If so, how and when?"). A 2 by 3 chi-square test was used to examine the relationship between "vocal change noted," and no noted health conditions and health conditions coded as having a lesser or greater potential to affect voice. This relationship was not significant $\left(x^{2}=5.035, \mathrm{p}=.08\right)$; yet, a significant relationship was noted when the "no reported health conditions" and "health conditions with lesser potential to affect voice" data were consolidated into one category $\left(x^{2}=\right.$ 4.918, $\mathrm{p}=.026)$. No significant relationship was found when comparing "Noted Vocal Change" with "Surgery with greater potential to affect vocal change" $\left(x^{2}=.02, \mathrm{p}=.88\right)$. These results are provided in tables 5,6 , and 7 .

\section{Are older adults aware of the resources available to them to address voice-related concerns?}

Of the 31 participants, 17 of them, or $54 \%$ indicated that they were aware of some resources that were available to address voice-related concerns. Nine out of the 12 individuals, or $75 \%$, that noted voice changes were aware of resources available to them to address vocal concerns. Seven of the 19 , or $36 \%$ of those who indicated that they had not experienced vocal changes, were aware of resources (e.g., SLPs, ENTs) for vocal concerns.

\section{Additional Findings}

The RSES was significantly correlated with both the VSES $\left(r_{x y}=-547, \mathrm{p}=.002\right)$ and VHI $\left(r_{x y}=-.343, \mathrm{p}=.04\right)$. 


\section{CHAPTER V: DISCUSSION}

\section{Summary of Study}

The purpose of the current study was to explore perceived voice handicap and selfesteem levels in older adults, as well as to examine whether men and women's perceived vocal handicap and self-esteem differed significantly. The study also sought to determine if cognitive status impacted participant results, and if older adults were aware of age-related voice changes and resources available to address voice-related concerns (e.g., SLPs, ENTs).

\section{Aging, Perceived Voice Symptoms, and Self-Esteem}

No significant relationship was found between age, perceived vocal function, and perceived self-esteem. VHI scores (used to examine perceived vocal function) ranged from 0 to 34. The higher the VHI score, the more an individual's voice is thought to impact vocal quality of life and lead to vocal handicap. Twelve out of the 31 participants had a score of 10 or more on the VHI. A score of 33.69, however, is the threshold for mild vocal handicap. Thus, the majority of the participants in this study did not appear to have voice concerns that would be classified at even the mild level.

Visual inspection of the data showed a potential trend towards minimal voice users scoring higher on the VHI and lower on the RSES. The statistical analysis revealed, however, that this was not significant. A low score on the RSES signifies a low level of self-esteem, while a higher VHI score indicates greater perceived vocal handicap.

\section{Cognition, Perceived Vocal Quality and Function, and Self-Esteem}

Only two individuals failed the cognitive screener in this study. Thus, it was not possible to determine how or if cognitive functioning impacts the self-esteem levels and perceived vocal handicap; however, no significant relationship was found between performance on the cognitive 
screener (the SAGE) and self-esteem (as scored on the RSES). Most of the participants received the maximum score of 22 . The rest of the participants were within the normal range or slightly below. Older adults have an increased likelihood of declined cognition (Diehl, Wahl, Barrett, et al., 2014), thus the reason for electing to use the SAGE was to ensure that participants' questionnaire responses were not confounded by cognitive impairment.

\section{Older Men’s Versus Older Women's Self-Esteem and Perceived Vocal Quality and Function}

There was a total of 19 women and 12 men in the study. Men had slightly higher selfesteem and slightly greater vocal handicap than women, but none of the data were statistically significant. Higher levels of self-esteem in men is consistent with the literature (Robins, Trzeniewski, Tracy, Gosling, \& Potter, 2002), yet higher VHI levels in men contrast with past research findings which indicate that women are more prone to vocal concerns (Gregory, Chandran, Lurie, \& Sataloff, 2012). That being said, given that differences were not significant, this sample of individuals was similar across gender in regard to levels of self-esteem and perceived vocal quality and function.

\section{Awareness of Voice Changes}

Those individuals who noticed vocal change averaged VHI scores almost double of those who did not notice vocal change. A significant relationship was found between individuals indicating life-span voice changes and mentioning medical conditions coded as having a greater potential to produce voice change. Vocal changes may be more noticeable when individuals have chronic conditions that may have secondary effects on the voice (e.g., asthma, thyroid deficiencies). Surgical procedures coded as having a greater potential to produce vocal change did not exhibit a significant relationship with perceived age-related vocal change. 


\section{Adults' Awareness of Resource}

More than half of the participants indicated an awareness of resources (e.g., SLPs, ENTs) that could address voice-related concerns. Individuals were approximately 2 times more likely to be aware of vocal resources if they indicated noticing lifespan vocal changes versus if they did not notice these changes. Thus, just as those with health conditions with the potential to affect the voice, individuals are more likely to take an interest in how to address vocal issues or changes when they perceive a negative vocal change. These results may demonstrate that those who are aware of vocal changes are much more likely to know how to seek help for voice-related concerns than those without any awareness of lifespan voice changes.

\section{Additional Findings}

The VSES's correlation with the RSES and the VHI provides preliminary evidence that this novel measure is a valid tool to measure voice-related self-esteem. Further research is required to further examine the reliability and validity of the VSES for its future use.

\section{Impressions}

The results from the sample show that self-esteem, age, and perceived vocal function are not significantly correlated. These findings may result from most participants falling below the "mild" VHI score, indicating that vocal concerns were not particularly prevalent among this cohort. However, those who had high VHI scores and also high RSES scores may demonstrate how some individuals are less affected by the sound or ability of their voices. It may also indicate that not all older adults will have concerns of perceived dysphonia due to age-related voice changes (Plank, Schneider, Eysholdt, Schutzenberger, \& Rosanowski, 2011). These individuals may also use more coping strategies to help them adjust to voice changes in older adulthood (Oliveira et al., 2012). 
Men and women received very similar average scores on the VHI, RSES, and VSES scores. Women's “vocal use" ratings were also lower than men's, but only by .2\%. The literature discusses how women over the age of 80 years often have increases in self-esteem while men's tend to drop during this time (Robins, et al., 2002). This may explain why both men and women in this study had similar self-esteem levels.

It is not surprising that individuals who noticed lifespan vocal changes were more likely to have vocal conditions with the potential to affect the voice and higher VHI scores. Increased awareness of vocal change may be influenced by previous health conditions that impact vocal ability and function. Previous experiences or exposure to vocal concerns in this case, may have created an improved awareness of voice changes for participants. The same principle of exposure creating awareness may be applied to the final research question regarding awareness of vocal resources. If individuals noticed vocal changes, they were more likely to be aware of resources for vocal concerns. Over half of all participants were aware of resources to address vocal concerns, while $75 \%$ of individuals who noticed vocal change were aware of vocal resources. While these odds are better than the $36 \%$ of those who did not notice vocal change and were aware of resources, there is clearly a need for more education among both subgroups of individuals.

\section{Limitations}

A limitation of this research was the small sample size and the relatively healthy sample both vocally and cognitively. It is difficult to draw conclusions about self-esteem and voice handicap since few participants had major voice concerns or complaints. Likewise, the relationship between cognition, self-esteem, and vocal function could not be adequately examined since participants had largely normal cognition. 
Although men scored higher on the VHI and RSES, these differences were not statistically significant. While these findings indicate similar levels of perceived vocal handicap and self-esteem for males and females, there were almost twice as many female participants; potentially skewing results.

In addition to sample size limitations, only the perception of voice difficulties was analyzed in this study, since diagnosis of specific voice disorders and presbyphonic changes requires laryngeal imaging and collaboration with an ENT. As a result, it was impossible to know the degree to which any participants were experiencing structural changes to the larynx typically associated with aging.

\section{Conclusion and Further Research}

The aim of this research was to explore the relationship between the perceptions of vocal aging and self-esteem in older adults. Continued increases in the older adult population in the coming decades warrants special attention to the healthcare provided to these individuals, including vocal changes and disorders. Preparation for competently serving older adults clinically requires a greater understanding of the psychosocial consequences of vocal aging.

While this study did not find a significant relationship between perceived vocal function and lower self-esteem, the most apparent outcome of the data was that individuals with health conditions with a greater potential to impact the voice were more likely to note lifespan vocal changes and knowledge of resources to address vocal concerns. Regardless of this awareness, there is still a great need for increased awareness through educational outreach from professionals such as SLPs and ENTs.

Future research should target a larger population of older adults with similar numbers of male and female participants with mild to severe perceived vocal handicap, as measured by the 
VHI, in order to determine how, and if greater perceived vocal handicap is related to lower selfesteem. Further, future studies might examine self-esteem via the RSES in a sample of individuals diagnosed with presbyphonia within a clinical voice center. Likewise, while the VSES showed preliminary evidence of validity, this tool requires that refining on the VSES be completed, so it may be used as a means to analyze the relationship between voice handicap and levels of self-esteem in older adults

It would also be beneficial for future studies to analyze the difference between scores of older adults and younger individuals. More specifically, are older or younger adults more prone to potential emotional side effects as a result of voice disorders? Studying this question and further questions regarding the aging voice and self-esteem, assists professionals and family and friends of individuals with voice disorders understand their needs and concerns. The better professionals understand age-related voice problems and associated psychosocial factors, the more they can strive to improve the quality of life for older adults in the future. 


\section{REFERENCES}

American Speech-Language-Hearing Association. (2017). Voice Disorders. Available from ww.asha.org/policy.

Behlau, M., Hogikyan, N. D., \& Gasparini, G. (2007). Quality of life and voice: study of a brazilian population using the voice-related quality of life measure. Folia Phoniatrica et Logopaedica, 59(6), 286-96.

Berg, E. E., Hapner, E., Klein, A., Johns, M. M. (2008). Voice therapy improves quality of life in age-related dysphonia: a case-control study. Journal of Voice, 22(1), 70-4.

Boone, D., McFarlane, S. C., Von Berg, S. L., \& Zraick, R. L. (2014). The voice and voice therapy. Pearson.

Bosson, J. K., Swann, W. B., \& Pennebaker, J. W. (2000). Stalking the perfect measure of implicit self-esteem: the blind men and the elephant revisited? Journal of Personal Social Psychology, 79(4), 631-43.

Close, L. G., \& Woodson, G. E., (1989). Common upper airway disorders in the elderly and their management. Geriatrics, 44, 67-71.

Cohen, S.M. (2010). Self-reported impact of dysphonia in a primary care population: an epidemiological study. Laryngoscope, 120, 2011-2032.

Colby, S. L., Ortman, J. M., (2015). Projections of the Size and Composition of the U.S. Population: 2014 to 2060 Population Estimates and Projections Current Population Reports. Census.gov.

Cooley, C. H. (1964). Human nature and the social order. New York: Schocken Books. 
Creighton, Fx, Jr., Poliashenko, S. M., Statham, M. M., Abramson, P., \& Johns, M. M. (2013). The growing geriatric otolaryngology patient population: a study of 131,700 new patient encounters. Laryngoscope, 123(1), 97-102.

Crocker, J., \& Wolfe, C. T. (2001). Contingencies of self-worth. Psychological Review, 108, $593-623$.

de Araújo Pernambuco, L., Espelt, A., Balata, P. M., \& de Lima, K. C. (2015). Prevalence of voice disorders in the elderly: a systematic review of population-based studies. European Archives of Otorhinolaryngology, (10), 2601-9.

Decoster, W., \& Debruyne, F. (2000). Longitudinal changes: facts and interpretation. Journal of Voice, 14, 184-193.

Diehl, M., Wahl, H. W., Barret, A. E., Brothers, A. F., Miche, M., Montepare, J. M.,...\& Wurm, S. (2014). Awareness of aging: theoretical considerations on an emerging concept. Developmental Review, 34(2), 93-113.

Dietrich, M., Verdolini Abbott, K., Gartner-Schmidt, J., \& Rosen, C. A., (2008). The Frequency of Perceived Stress, Anxiety, and Depression in Patients with Common Pathologies Affecting Voice. Journal of Voice, 22(4), 472-88.

Epstein, R., Hirani, S. P., Stygall, J., \& Newman, S. P. (2009). How do individuals cope with voice disorders? Introducing the voice disability coping questionnaire. Journal of Voice, 23(2), 209-217.

Etter, M. N., Stemple, J. C., \& Howell, D. M. (2013). Defining the lived experience of older adults with voice disorders. Journal of Voice. 27(1), 61-67. 
Fein, D. J. (1983). Projections of speech and hearing impairments to 2050. ASHA, 25, 11.

Golub, J. S., Chen, P., Otto, K. J., Hapner, E., \& Johns, M. M. (2006). Prevalence of perceived dysphonia in a geriatric population. Journal of American Geriatrics Society, 54(11), 1736-1739.

Gregory, N. D., Chandran, S., Lurie, D., \& Sataloff, R.T. (2012). Voice disorders in the elderly. Journal of Voice, 26, 254-258.

Harris, M. A., Donnellan, M. B., \& Trzesniewski, K. H. (2018). The lifespan self-esteem scale: initial validation of a new measure of global self-esteem. Journal of Personality Assessment, 100(1), 84-95.

Hirano, M., Kurita, S., Sakaguchi, S. (1989). Ageing of the vibratory tissue of human vocal folds. Acta Oto-laryngologica, 107(5-7), 428-33.

Hollien, H. (1987). Old voices: what do we really know about them? Journal of Voice, 1, 2-17.

Honjo, I., Isshiki, N. (1980). Laryngoscopic and voice characteristics of aged persons. Archives of Otolaryngology, 106, 149-150.

Jacobson, B. H., Johnson, A., Grywalski, C., Silbergleit, A., Jacobson, G., Benninger, M. S., Newman, C. W. (1997). The voice handicap index (VHI) development. American Journal of Speech-Language Pathology, 6, 66-70.

James, W. (1983). The principles of psychology. Cambridge, MA: Harvard University Press.

Kahane, J. C. (1987). Connective tissue in the larynx and their effects on voice. Journal of Voice, $1,27-30$.

Kendal, K. (2007). Presbyphonia: a review. Current Opinion in Otolaryngology \& Head and Neck Surgery, 15, 137-140. 
Lass, N.J., Ruscello, D.M., Bradshaw, K.H., \& Blankenship, B.L. (1991). Adolescents' perceptions of normal and voice-disordered children. Journal of Communication Disorders, 24(4), 267-274.

Lass, N.J., Ruscello, D.M., Stout, L.L., \& Hoffmann, F.M. (1991). Peer perceptions of normal and voice-disordered children. Folia Phoniatrica et Logopaedica, 34, 29-35.

Levenson, H. (1973). Multidimensional locus of control in psychiatric patients Consult. Clinical Psychology, 41, 397-404.

Linville S. E. (1987). Acoustic-perceptual studies of aging voice in women. Journal of Voice, 1, 44-48.

Lundy, D. S., Silva, C., Casiano, R. R., Lu, F., \& Xue. (1998). Causes of hoarseness in elderly patients. Otolaryngology- Head and Neck Surgery, 118(4), 481-485.

Melo, E. C. M., Mattioli, F.M., Brasil, O. C. O., Behlau, M., Pitaluga, A. C. A., Melo, D. M. (2001). Disfonia infantil: aspectos epidemiológicos. Revista Brasileira de Otorrinolaringologia, 67(6), 804-7.

Mezzedimi, C., DiFrancesco, M., Livi, W., Spinosi, M. C., \& DeFelice, C. (2017). Objective evaluation of presbyphonia: spectroacoustic study on 142 patients with praat. Journal of Voice, 31, 25-257.

Mirza, N., Ruiz, C., Baum, E.D., \& Staab, J.P. (2003). The prevalence of major psychiatric pathologies in patients with voice disorders. Ear Nose \& Throat Journal, 808-812.

Monini, S., Filippi, C., Baldini, R., \& Barbara, M. (2015). Perceived disability from hearing and voice changes in the elderly. Geriatrics Gerontology International, 15(2), 147-155. 
Mullen, S. P., Gothe N. P., McAuley, E. (2013). Evaluation of the factor structure of the rosenberg self-esteem scale in older adults. Personality and Individual Differences, 54(2), $153-157$.

(Oliveira et al., 2012). Coping strategies in Voice Disorders of a brazillian population. Journal of Voice, 26(2), 205-213.

Orth, U., Maes, J., \& Schmitt, M. (2001). Self-esteem development across the life span: A longitudinal study with a large sample from Germany. Developmental Psychology, $51(2), 248-259$.

Orth, U., Trzesniewski, K. H., \& Robins, R. W. (2010). Self-esteem development from young adulthood to old age: A cohort-sequential longitudinal study. Journal of Personality and Social Psychology, 98, 645-658.

Paixao, C. L. B., Siqueira, L. T. D., Coelho, A. C., Brasolotto, A. G., \& Silverio, K. C. A. (2015). Is there agreement between parents and children about their vocal behavior? Common Disorders, 27(4), 750-9.

Plank, C., Schneider, S., Eysholdt, U., Schutzenberger, A., \& Rosanowski, F. (2011). Voice and health-related quality of life in the elderly. Journal of Voice, 25, 265-268.

Pontes, P., Brasolotto, A., \& Behlau, M. (2005). Glottic characteristics and voice complaint in the elderly. Journal of Voice, 19, 84-946.

Pontes, P., Yamasaki, R., Behlau, M. (2006). Morphological and functional aspects of the senile larynx. Folia Phoniatrica et Logopaedica, 58, 51-158 7.

Ramig, L. O., \& Verdolini, K. (1998). Treatment efficacy: voice disorders. Journal of Speech Language and Hearing Research, 41(1), 101-16. 
Robins, R. W., Trzesniewski, K. H., Tracey, J. L., Gosling, S. D., Potter, J. (2002). Global selfesteem across the life span. Psychology and Aging, 17(3), 423.

Rosenberg, M. (1965). Society and the adolescent self-image. Princeton, NJ: Princeton University Press.

Roy, N., Merrill, R. M., Gray, S. D., \& Smith, E. M. (2005). Voice disorders in the general population: prevalence, risk factors, and occupational impact. Laryngoscope, 115 (11), $1988-1995$.

Roy, N., Stemple J., Merill, R. M., \& Thomas L. (2007). Epidemiology of voice disorders in the elderly: preliminary findings. Laryngoscope, 117, 628-633.

Roy, N., Stemple J., Merrill, R. M., \& Thomas, L. (2007). Dysphagia in the elderly: preliminary evidence of prevalence, risk factors, and socioemotional effects. Annals of Otology, Rhinology, \& Laryngology, 116, 858-865.

Ruscello, D.M., Lass, N.J., \& Podbesek, J. (1988). Listeners' perceptions of normal and voicedisordered children. Folia Phoniatrica et Logopaedica 40, 290-296.

Ryan, W. J., \& Burk, K. W., (1974). Perceptual and acoustic correlates of aging in the speech of males. Journal of Communication Disorders, 7, 181-192.

Sauder, C., Roy, N., Tanner, K., Houtz, D. R., \& Smith, M. E. (2010). Vocal function exercises for presbylaryngis: A multidimensional assessment of treatment outcomes. Annals of Otology Rhinology and Laryngology-Including Supplements, 119(7), 460.

Scharre, D. W., Chang, S-I., Murden, R, A., Lamb, J., Beversdorf, D, Q., Kataki, M., Naharaja, H, N., \& Bornstein, R, A (2010). Self-administered gerocognitive examination (sage): A brief cognitive assessment instrument for mild cognitive impairment (mci) and early dementia. Alzheimer Disease and Associated Disordisorders, 24, 64-71. 
Schimmack, U., Diener, B. (2003). Predictive validity of explicit and implicit self-esteem for subjective well-being. Journal of Research in Personality, 37, 100-106.

Schwartz, S. R., Cohen, S. M., Dailey, S. H., Rosenfeld, R, M., Deutsch, E. S., Gillespie, B.,... Patel, M. M. (2009). Clinical practice guideline: hoarseness (dysphonia).

Otolaryngology- Head and Neck Surgery, 141(3), 1-31.

Sinard, R. J., \& Hall, D. (1998). Geriatrics advisor. The aging voice: how to differentiate disease from normal changes. Geriatrics, 53(7), 76-79.

Souza, B. O., Nunes, R. B., Friche, A., \& Gama, A. C. G (2017). Analysis of the quality of life related to voice in children. $C o D A S, 29(2)$.

Steiger, A. E., Allemand, M., Robins, R. W., \& Fend, H. A. (2014). Low and decreasing selfesteem during adolescence predict adult depression two decades later. Journal of Personality and Social Psychology, 106, 325-338.

Stemple, J. C. (2000). Voice therapy: clinical studies. San Diego, California: Singular.

Stemple, J. C., Roy, N., \& Klaben, B. K. (2014). Clinical voice pathology: theory and management. Plural Publishing.

Tamres, L. K., Janicki, D., \& Helgeson, V. S. (2002). Sex differences in coping behavior: a meta-analytic review and an examination of relative coping. Personality and Social Psychology, 6, 2-30.

Titze, I. E. (1994). Principles of voice production. Englewood Cliffs, NJ: Prentice-Hall.

Turley, R., \& Cohen, S. (2009). Impact of voice and swallowing problems in the elderly. Otolaryngology-Head and Neck Surgery, 140(1), 33-36.

Vaca, M., Mora, E., Cobeta, I. (2015). The aging voice: influence of respiratory and laryngeal changes. Otolaryngology \& Head and Neck Surgery, 153(3), 409-413. 
Verdonck-de Leeuw, I. M., \& Mahieu, H. F. (2004). Vocal aging and the impact on daily life: a longitudinal study. Journal of voice, 18(2), 193-202.

Wilson, D. K. (1979). Voice problem of children. 2nd ed. Baltimore: Waverly Press; p. 238.

Weismer, G., \& Liss, J. M. (1991). Acoustic/perceptual taxonomies of disordered speech in Dysarthria and apraxia of Speech: Perspectives on Management, edited by C. Moore, K. Yorkston, and D. (Brookes, Baltimore), 245-270.

Ximenes, F. J. A., Tsuji, D. H., do Nascimento, P. H., \& Sennes, L. U. (2003). Histologic changes in human vocal folds correlated with aging: a histomorphometric study. The Annals of Otology, Rhinology \& Laryngology, 112(10), 894-898.

Xue, S. A., \& Hao, G. J. (2003). Changes in the human vocal tract due to aging and the acoustic correlates of speech production: A pilot study. Journal of Speech, Language and Hearing Research, 46(3), 689-701.

Zhang, X., Chen, X., Ran, G., \& Ma, Y. (2016). Adult children's support and self-esteem as mediators in the relationship between attachment and subjective well-being in older adults. Personality and Individual Differences, 97, 229-233.

Ziegler, A. \& Hapner, E. (2013). The behavioral voice-lift learn how slps can help restore the youthful voice of an aging population. The ASHA Leader, 18.

Zraick, R. I., Gregg, B. A., \& Whitehouse, E. L. (2006). Speech and voice characteristics of geriatric speakers: A review of the literature and a call for research and training. Journal of Medical Speech-Language.

Zur, K. B., Cotton, S., \& Kelchner, L., Baker, S., Weinrich, B., \& Lee, L. (2007). Pediatric voice handicap index (pVHI): a new tool for evaluating pediatric dysphonia. International Journal of Pediatric Otorhinolaryngology, 71, 77-82. 
Table 1

Participant Demographics

\begin{tabular}{|c|c|c|c|c|c|}
\hline Participant & Age & Gender & $\begin{array}{l}\text { Reported Vocal } \\
\text { Change }\end{array}$ & $\begin{array}{l}\text { Health } \\
\text { Status* }\end{array}$ & SAGE score \\
\hline 1 & 76 & Female & lower & 3 & 22 \\
\hline 2 & 71 & Male & - & 2 & 18 \\
\hline 3 & 68 & Female & - & 1 & 21 \\
\hline 4 & 75 & Male & - & 3 & 22 \\
\hline 5 & 85 & Female & lower & 3 & 22 \\
\hline 6 & 67 & Male & hoarse & 3 & 21 \\
\hline 7 & 79 & Male & - & 3 & 20 \\
\hline 8 & 78 & Female & hoarse & 3 & 20 \\
\hline 9 & 72 & Male & - & 3 & 21 \\
\hline 10 & 70 & Female & - & 3 & 22 \\
\hline 11 & 70 & Female & - & 1 & 22 \\
\hline 12 & 67 & Female & lower & 3 & 21 \\
\hline 13 & 75 & Female & hoarse & 3 & 22 \\
\hline 14 & 74 & Female & soft & 1 & 21 \\
\hline 15 & 74 & Female & - & 1 & 21 \\
\hline 16 & 82 & Female & - & 2 & 22 \\
\hline 17 & - & Female & - & 2 & 26 \\
\hline 18 & 67 & Male & - & 2 & 20 \\
\hline 19 & 76 & Male & - & 1 & 21 \\
\hline 20 & 75 & Female & hoarse & 3 & 15 \\
\hline 21 & 78 & Male & lower & 2 & 17 \\
\hline 22 & 74 & Female & - & 2 & 22 \\
\hline 23 & 74 & Female & - & 2 & 17 \\
\hline 24 & 73 & Female & - & 3 & 21 \\
\hline 25 & 80 & Female & - & 2 & 13 \\
\hline 26 & 79 & Female & - & 2 & 21 \\
\hline 27 & 82 & Female & - & 2 & 17 \\
\hline 28 & 77 & Female & - & 1 & 22 \\
\hline 29 & 69 & Male & lower & 2 & 22 \\
\hline 30 & 70 & Male & hoarse & 3 & 22 \\
\hline 31 & 66 & Male & lower & 2 & 22 \\
\hline
\end{tabular}

*Note: $1=$ Healthy, $2=$ Health Concern Not Related to Vocal Change, $3=$ Health Concern Related to Vocal Change 
Table 2

Health Conditions Listed by Participants with Greater Potential to Impact Vocal Function

\begin{tabular}{ll}
\hline & $\mathrm{N}^{*}$ \\
\hline Arthritis & 5 \\
Allergies & 4 \\
Thyroid deficiency & 2 \\
Chronic obstructive pulmonary disease & 1 \\
Acid reflux & \\
Asthma & 1 \\
Difficulty breathing & 1 \\
\end{tabular}

*Note: 2 participants listed multiple (2) health conditions 
Table 3

Number of Individuals Who Indicated Specific Types of Surgery with Potential to Result in Vocal Change

\begin{tabular}{ll} 
Health Conditions & $\mathrm{N}^{*}$ \\
\hline Tonsillectomies & 8 \\
Hysterectomy & 8 \\
Thyroidectomy & 3 \\
Coronary arterial bypass graft & 2 \\
Hypothyroidism & 1 \\
Malignant melanoma of the neck & 1 \\
Goiter around the trachea & 1 \\
Deviated septum & 1 \\
Sinus conditions & 1 \\
Tongue cancer & 1 \\
\hline
\end{tabular}

*Note: 4 participants listed multiple (2) health conditions 
Table 4

Vocal Change Described by Participants

\begin{tabular}{ll} 
Vocal Change: & N \\
\hline Raspy/rough/ hoarse & 5 \\
Lowering of voice & 6 \\
Soft/weak & 1 \\
\end{tabular}


Table 5

Vocal Change Noted in Healthy Individuals and those with Health Conditions with a Greater or Lesser Potential to Affect Vocal Change

\begin{tabular}{lccc}
\hline & & Health condition with lesser \\
Vocal change noted & Healthy & potential to affect vocal change & $\begin{array}{l}\text { Health conditions with } \\
\text { greater potential to affect } \\
\text { vocal change }\end{array}$ \\
\hline Yes & 1 & 3 & 8 \\
No & & 9 & 5 \\
\hline
\end{tabular}


Table 6

Number of Participants Who Did or Did Not Indicate Vocal Change in Conjunction with Surgical History Coded as Having Greater or Lesser Potential to Affect Voice

\begin{tabular}{lcc}
$\begin{array}{l}\text { Vocal change } \\
\text { noted }\end{array}$ & $\begin{array}{l}\text { No Surgery/Surgery with lesser } \\
\text { potential to affect vocal change }\end{array}$ & $\begin{array}{l}\text { Surgery with greater potential to } \\
\text { affect vocal change }\end{array}$ \\
\hline Yes & 6 & 6 \\
No & 9 & 10 \\
\hline
\end{tabular}


Table 7

Number of Participants Who Did or Did Not Indicate Vocal Change in Conjunction with Health History Coded as Having Greater or Lesser Potential to Affect Voice

\begin{tabular}{lcc} 
Vocal Change Noted & $\begin{array}{l}\text { Health Not Related to } \\
\text { Vocal Change }\end{array}$ & $\begin{array}{l}\text { Health Condition Related to } \\
\text { Vocal Change }\end{array}$ \\
\hline Yes & 4 & 8 \\
No & 14 & 5 \\
\hline
\end{tabular}




\section{Table 8}

Average Voice Handicap Index (VHI), Rosenberg Self-Esteem Scale (RSES), and Voice SelfEsteem Scale (VSES)

\begin{tabular}{lcl} 
Questionnaire & Men Mean (SD): & Women Mean (SD): \\
\hline VHI & $9.63(9.8617)$ & $8.25(5.3975)$ \\
RSES & $35.3(4.2711)$ & $33.2(3.4417)$ \\
& & $40(4.7871)$ \\
VSES & $41.8(5.1540)$ & \\
\hline
\end{tabular}


APPENDIX A: DEMOGRAPHIC QUESTIONS

Please answer the following questions:

Date of Birth:

You identify as (please circle): Male Female Other

Indicate the city and state where you currently live.

Please list all current health conditions and indicate approximate year diagnosed.

Please list any resolved past medical conditions and approximate years diagnosed and resolved.

Please list all current medications and dosages.

Have you ever seen a specialist (i.e., ear nose and throat doctor, primary care doctor, speech-language pathologist, etc.) for a voice-related concern or concerns? (please circle): YES NO If yes,

Please provide each specific voice-related concern(s) that caused you to seek help, approximate date(s) you sought out services, and the type of specialist (i.e., ear nose and throat doctor, primary care doctor, speech-language pathologist, etc.) seen regarding your concern(s). 
Please list any current voice-related concern(s), for which you have not sought out medical assistance (i.e., frequent hoarseness, difficulty speaking for a prolonged period of time, etc.)

List all surgeries. Please provide the reason for the surgery and the year the surgery was performed.

Have you ever been diagnosed with a voice disorder? If so, please indicate the diagnosis and year you were diagnosed. If diagnosed with multiple disorders please list each diagnosis and date of diagnosis.

Have you ever had voice therapy with speech-language pathologist? (please circle): YES NO

a. If so, what year did you receive therapy and for what reason? 
b. If you did attend therapy, how long did you attend therapy for (i.e., number of sessions or number of months)?

List the ways in which you use your voice daily and star activities for which you use your voice most frequently (e.g., singing, participating in classes, etc.)

Rate the degree to which you use your voice daily. (Please circle): Hardly at all ( $0-20 \%$ of waking hours) Minimally (20-40\% of waking hours)

Moderately ( $40 \%-60 \%$ of waking hours) Intensively ( $60-80 \%$ of waking hours Almost all the time ( $80 \%-100 \%$ of waking hours)

Do you have any vocal training/experience (i.e., voice lessons, choir participation, theater performance, radio announcing)? (Please circle): YES NO

a. If yes, please list each type of training and experience here with year or span of years for which you participated in each.

Has the sound of your voice changed over your lifetime? If so, how and when? 
Are you aware of any resources or supports that you could contact if you had trouble with your voice? Please list.

Please provide any additional comments if applicable: 


\section{Instructions:}

Below is a list of statements dealing with your general feelings about yourself. Please circle the response indicating how strongly you agree or disagree with each statement.

1. On the whole, I am satisfied with myself.
Strongly Agree
Agree
Disagree
Strongly Disagree

2. At times I think I am no good at all.

Strongly Agree Agree Disagree Strongly Disagree

3. I feel that I have a number of good qualities.

Strongly Agree Agree Disagree Strongly Disagree

4. I am able to do things as well as most other people.

Strongly Agree Agree Disagree Strongly Disagree

5. I feel I do not have much to be proud of.

Strongly Agree Agree Disagree Strongly Disagree

6. I certainly feel useless at times.

Strongly Agree Agree Disagree Strongly Disagree

7. I feel that I'm a person of worth, at least on an equal plane with others. Strongly Agree Agree Disagree Strongly Disagree

8. I wish I could have more respect for myself.

Strongly Agree Agree Disagree Strongly Disagree

9. All in all, I am inclined to feel that I am a failure.

Strongly Agree Agree Disagree Strongly Disagree

10. I take a positive attitude toward myself.
Strongly Agree
Agree
Disagree
Strongly Disagree 


\section{APPENDIX C: VOICE HANDICAP INDEX (VHI)}

$$
\text { (Jacobson, Johnson, Grywalski, et al.) }
$$

Instructions: These are statements that many people have used to describe their voices and the effects of their voices on their lives. Check the response that indicates how frequently you have the same experience.

$($ Never $=0$ points; Almost Never $=1$ point; Sometimes $=2$ points; Almost Always $=3$ points; Always $=4$ points)

\begin{tabular}{|c|c|c|c|c|c|}
\hline & Never & Almost Never & Sometimes & Almost & Always \\
\hline \multicolumn{6}{|l|}{$\begin{array}{l}\text { Fl. My voice makes it difficult } \\
\text { for people to hear me. }\end{array}$} \\
\hline \multicolumn{6}{|l|}{ P2. I run out of air when I talk } \\
\hline \multicolumn{6}{|l|}{$\begin{array}{l}\text { F3. People have difficulty under- } \\
\text { standing me in a noisy room }\end{array}$} \\
\hline \multicolumn{6}{|l|}{$\begin{array}{l}\text { P4. The sound of my voice } \\
\text { varies throughout the dav. }\end{array}$} \\
\hline \multicolumn{6}{|l|}{$\begin{array}{l}\text { F5. My family has difficulty } \\
\text { hearing me when I call them } \\
\text { throughout the house. }\end{array}$} \\
\hline \multicolumn{6}{|l|}{$\begin{array}{l}\text { F6. I use the phone less often } \\
\text { than I would like. }\end{array}$} \\
\hline \multicolumn{6}{|l|}{$\begin{array}{l}\text { E7. I'm tense when talking with } \\
\text { others because of mv voice. }\end{array}$} \\
\hline \multicolumn{6}{|l|}{$\begin{array}{l}\text { F8. I tend to avoid groups of } \\
\text { people because of my voice. }\end{array}$} \\
\hline \multicolumn{6}{|l|}{$\begin{array}{l}\text { E9. People seem irritated with } \\
\text { my voice. }\end{array}$} \\
\hline \multicolumn{6}{|l|}{$\begin{array}{l}\text { P10. People ask, "What's wrong } \\
\text { with your voice?" }\end{array}$} \\
\hline \multicolumn{6}{|l|}{$\begin{array}{l}\text { F11. I speak with friends, } \\
\text { neighbors, or relatives less often } \\
\text { because of my voice. }\end{array}$} \\
\hline \multicolumn{6}{|l|}{$\begin{array}{l}\text { F12. People ask me to repeat } \\
\text { myself when speaking face-to- } \\
\text { face. }\end{array}$} \\
\hline \multicolumn{6}{|l|}{$\begin{array}{l}\text { P13. My voice sounds creaky } \\
\text { and dry. }\end{array}$} \\
\hline & Never & Almost Never & Sometimes & $\begin{array}{l}\text { Almost } \\
\text { Always }\end{array}$ & Always \\
\hline $\begin{array}{l}\text { P 14. I feel as though I have to } \\
\text { strain to produce voice }\end{array}$ & & & & & \\
\hline
\end{tabular}




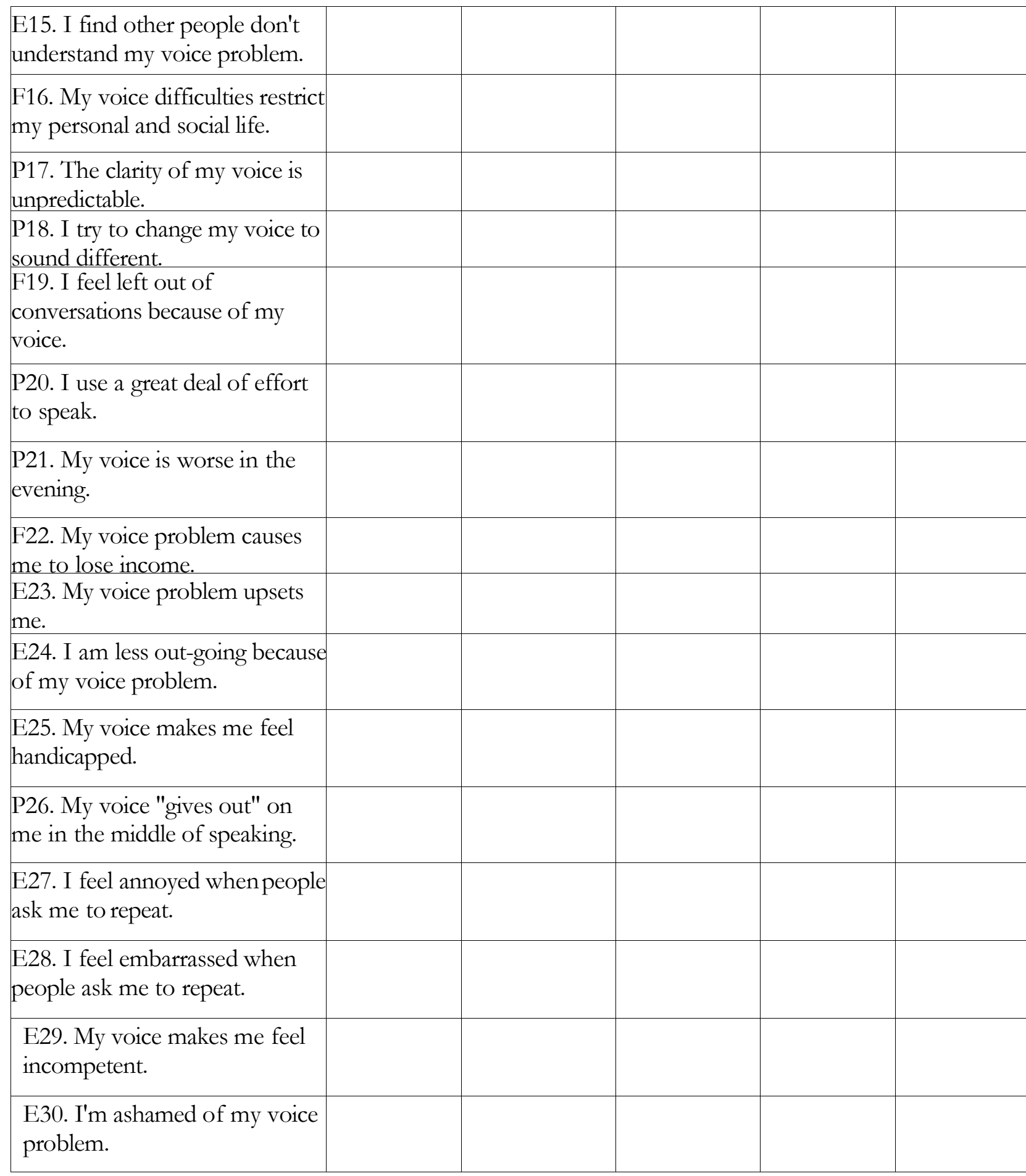

\section{Please circle the word that matches your voice today.}

Normal Mild Moderate Severe

\section{For researchers only:}

P_F_E_E___ Total_ 
Instructions

\section{APPENDIX D: VOICE SELF-ESTEEM SCALE (VSES)}

Below is a list of statements dealing with your general feelings about yourself and your speaking voice. Please indicate how strongly you agree or disagree with each statement.

1. On the whole, I am believe my speaking voice represents me well.
Strongly Agree
Agree
Disagree
Strongly Disagree

2. I sometimes feel negative about myself because of the way my speaking voice sounds.

Strongly Agree Agree Disagree $\quad$ Strongly Disagree

3. I feel that my speaking voice is a positive reflection of me as a person.
Strongly Agree
Agree
Disagree
Strongly Disagree

4. My speaking voice is just as good or better than most other individuals my age.
Strongly Agree
Agree
Disagree
Strongly Disagree

5. My voice makes me feel ashamed.
Strongly Agree
Agree
Disagree
Strongly Disagree

6. I feel useless at times because of the way my voice sounds.
Strongly Agree
Agree
Disagree
Strongly Disagree

7. My speaking voice allows me to communicate with others confidently.

Strongly Agree Agree Disagree Strongly Disagree

8. I would respect myself more if my speaking voice sounded/worked better.
Strongly Agree
Agree
Disagree
Strongly Disagree

9. I sometimes feel that I am a failure because of my speaking voice.

Strongly Agree Agree Disagree Strongly Disagree

10. I have a positive attitude toward myself, in part, because of my speaking voice. Strongly Agree Agree Disagree Strongly Disagree

11. I feel ashamed of my speaking voice so I avoid using the phone.
Strongly Agree
Agree
Disagree
Strongly Disagree

12. I would socialize with others more if I was more accepting of my speaking voice.

Strongly Agree Agree Disagree Strongly Disagree 


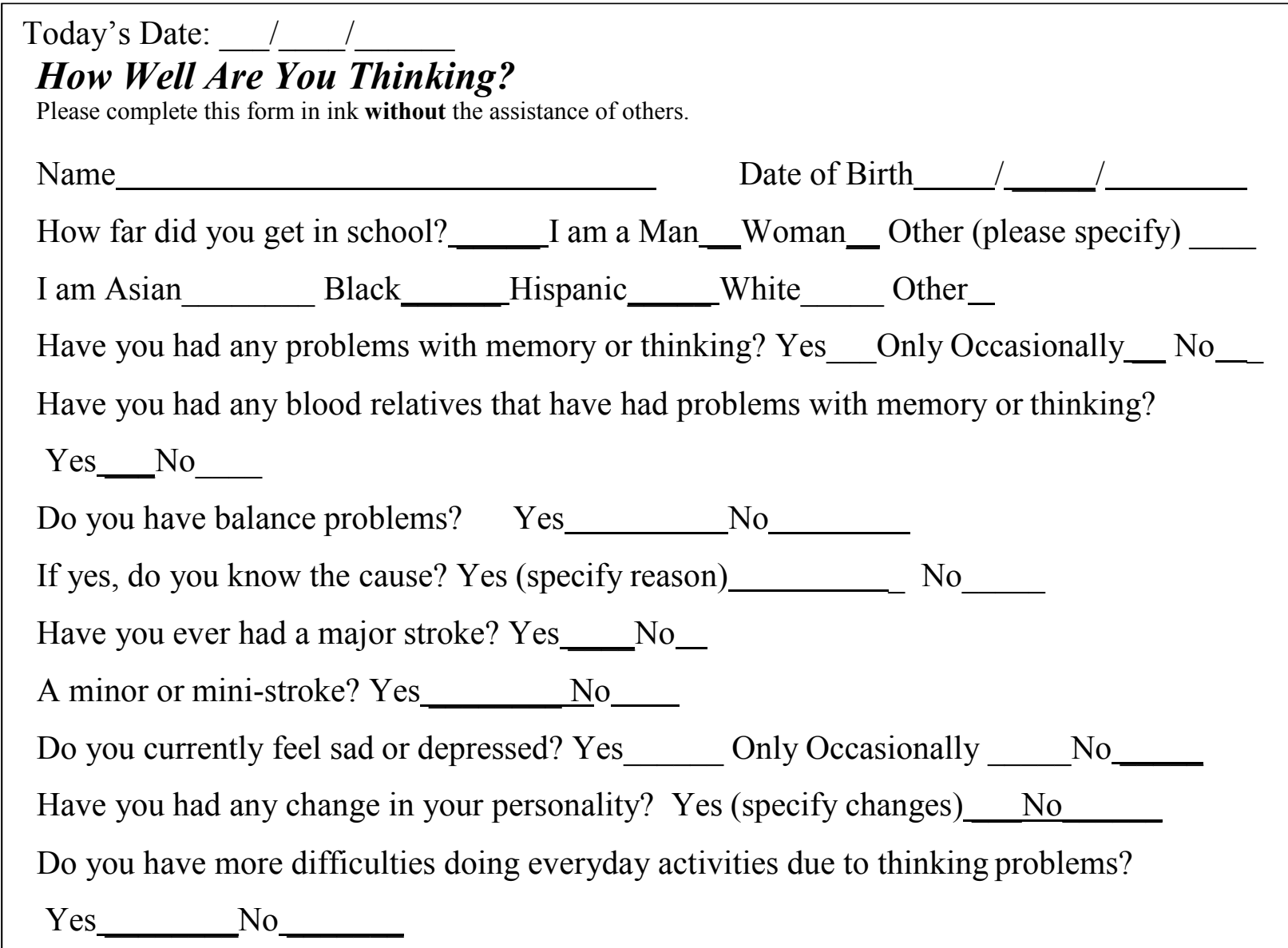

\section{What is today's date? (from memory - no cheating!) Month} Date Year

\section{Name the following pictures (don't worry about spelling):}
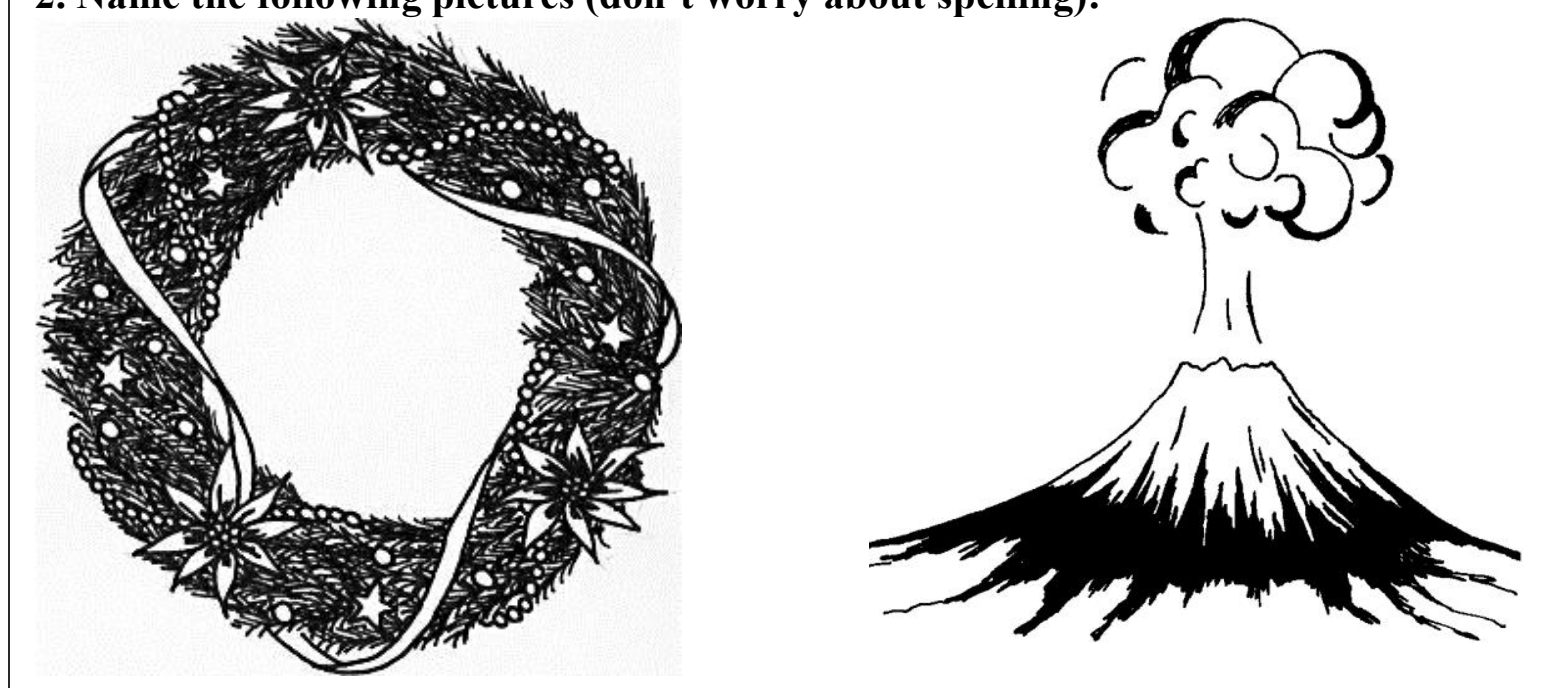


\section{Answer these questions:}

3. How are a watch and a ruler similar? Write down how they are alike. They both are... what?

4. How many nickels are in 60 cents?

5. You are buying $\$ 13.45$ of groceries. How much change would you receive back from a $\$ 20$ bill?

6. Memory Test (memorize these instructions). Do later only after completing this entire test:

At the bottom of the very last page: Write "I am done" on the blank line provided

\section{Copy this picture:}

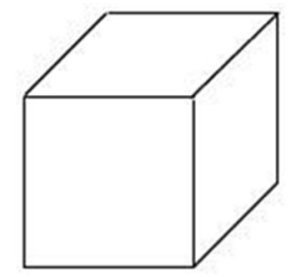

\section{Drawing test}

- Draw a large face of a clock and place in the numbers

- Position the hands for 5 minutes after 11 o'clock

On your clock, label "L" for the long hand and "S" for the short hand 
9. Write down the names of 12 different animals (don't worry about spelling):

Review this example (this first one is done for you) then go to question 10 below:

Draw a line from one circle to another starting at 1 and alternating numbers and letters (1 to $\mathrm{A}$ to 2 to $\mathrm{B}$ to 3 to $\mathrm{C}$ ).

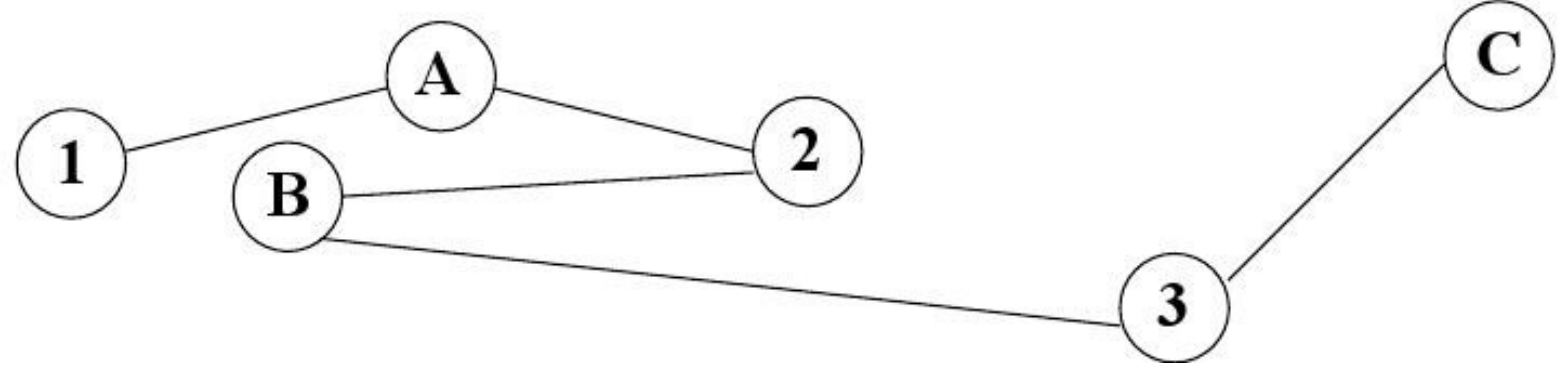

10. Do the following: Draw a line from one circle to another starting at 1 and alternating numbers and letters in order before ending at $\mathrm{F}$ ( 1 to $\mathrm{A}$ to 2 to $\mathrm{B}$ and so on).

(1)
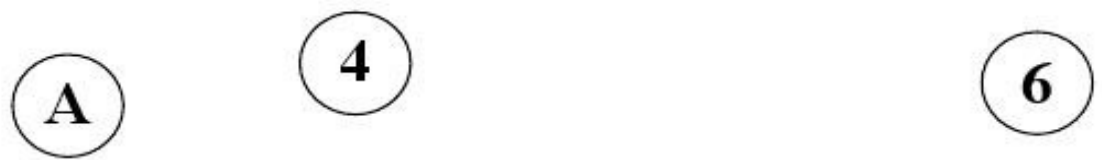

2

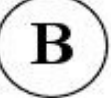

D

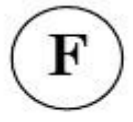

3

(C) 


\section{Review this example (this first one is done for you) then answer question 11 below:}

- Beginning with 1 triangle and 1 square

- Move 2 lines (marked with an X)

- To make 2 squares and no triangle

- Each line must be part of a complete square (no extra lines).

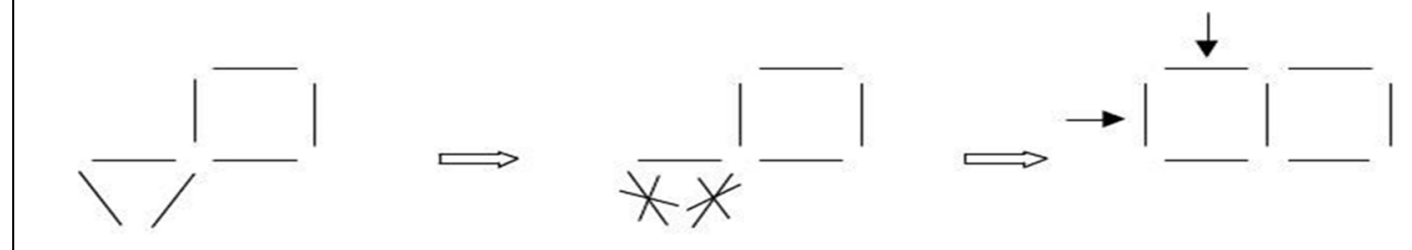

1 triangle, 1 square (example)
Move these 2 lines

(example)
Put them here (at arrows)

(example)

\section{Solve the following problem:}

- Beginning with 2 squares and 2 triangles

- Move 4 lines (mark with an X)

- $\quad$ To make 4 squares and no triangles

- Each line must be part of a complete square (no extra lines).

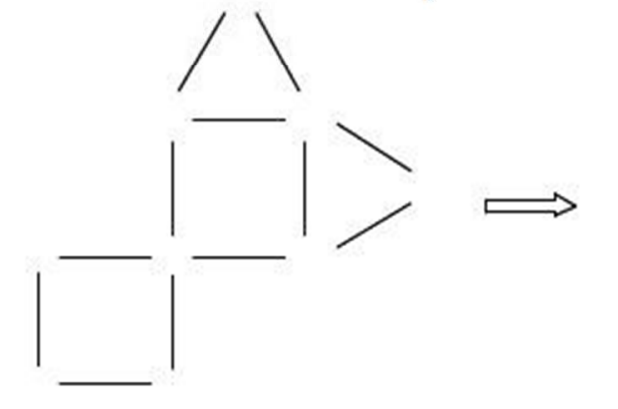

2 squares, 2 triangles
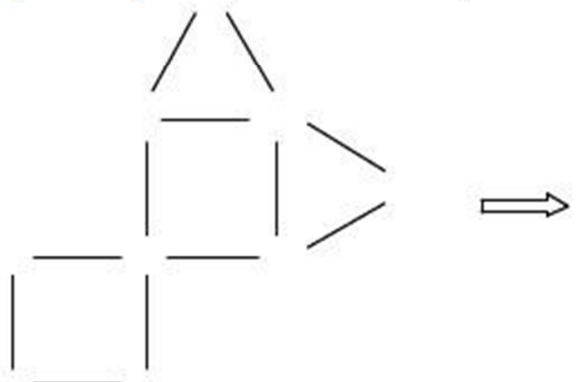

Move 4 lines

Mark with an $x$
Draw answer here 4 squares

\section{Have you finished?}

\section{STOP}


Copyright Information: Thesis

https://s100.copyright.com/CustomerAdmin/PLF.jsp?ref=6b561b11-aefa-4b92-ae68-

$\underline{\text { bf } 397 \mathrm{dc} 50 \mathrm{a} 8 \mathrm{c}}$

- Voice Handicap Index copyright

https://socy.umd.edu/about-us/rosenberg-self-esteem-scale

- Rosenberg Self-Esteem Scale Disclaimer 